\title{
Sulfur cycle and sulfate radiative forcing simulated from a coupled global climate-chemistry model
}

\author{
I.-C. Tsai ${ }^{1}$, J.-P. Chen ${ }^{1}$, P.-Y. Lin ${ }^{1}$, W.-C. Wang ${ }^{2}$, and I. S. A. Isaksen ${ }^{3}$ \\ ${ }^{1}$ Department of Atmospheric Sciences, National Taiwan University, Taiwan \\ ${ }^{2}$ Atmospheric Sciences Research Center, State University of New York at Albany, USA \\ ${ }^{3}$ Department of Geosciences, University of Oslo, Norway
}

Received: 1 August 2009 - Published in Atmos. Chem. Phys. Discuss.: 22 October 2009

Revised: 15 March 2010 - Accepted: 6 April 2010 - Published: 21 April 2010

\begin{abstract}
The sulfur cycle and radiative effects of sulfate aerosol on climate are studied with a Global tropospheric Climate-Chemistry Model in which chemistry, radiation and dynamics are fully coupled. Production and removal mechanisms of sulfate are analyzed for the conditions of natural and anthropogenic sulfur emissions. Results show that the 1985 anthropogenic emission tripled the global $\mathrm{SO}_{2}$ and sulfate loadings from its natural value of 0.16 and $0.10 \mathrm{TgS}$, respectively. Under natural conditions, the fraction of sulfate produced in-cloud is $74 \%$; whereas with anthropogenic emissions, the fraction of in-cloud sulfate production slightly increased to $76 \%$. Lifetimes of $\mathrm{SO}_{2}$ and sulfate under polluted conditions are estimated to be 1.7 and 2.0 days, respectively. The tripling of sulfate results in a direct radiative forcing of $-0.43 \mathrm{~W} \mathrm{~m}^{-2}$ (clear-sky) or $-0.24 \mathrm{~W} \mathrm{~m}^{-2}$ (all-sky), and a significant first indirect forcing of $-1.85 \mathrm{~W} \mathrm{~m}^{-2}$, leading to a mean global cooling of about $0.1 \mathrm{~K}$. Regional forcing and responses are significantly stronger than the global values. The first indirect forcing is sensitive to the relationship between aerosol concentration and cloud droplet number concentration which requires further investigation. Two aspects of chemistry-climate interaction are addressed. Firstly, the coupling effects lead to a slight decrease of $1 \%$ in global sulfate loading for both the cases of natural and anthropogenic added sulfur emissions. Secondly, only the indirect effect of sulfate aerosols yields significantly stronger signals in changes of near surface temperature and sulfate loading than changes due to intrinsic climate variability, while other responses to the indirect effect and all responses to the direct effect are below noise level.
\end{abstract}

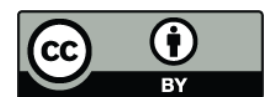

Correspondence to: J.-P. Chen (jpchen@as.ntu.edu.tw)

\section{Introduction}

Aerosol particles affect the Earth's energy budget directly by absorbing or scattering short-wave and long-wave radiation, and indirectly by influencing the structure and radiative properties of clouds through acting as cloud condensation nuclei and ice nuclei (Twomey, 1974; Albrecht, 1989). The perturbation of aerosols is believed to have significant impacts on climate, especially on regional scales (Ghan et al., 2001; Jones et al., 2001; Williams et al., 2001; Rotstayn and Penner, 2001; Ramanathan, 2001; Andersen, 2003; IPCC, 2007). Although numerous studies have estimated aerosol direct and indirect effects, the results are highly uncertain (Lohmann, 2005; IPCC, 2007). IPCC (2007) for instance, reported that the global annual mean radiative forcing of aerosol direct effect is about $-0.4 \mathrm{~W} \mathrm{~m}^{2}$ while for the first indirect effect (or the cloud albedo effect) the forcing ranges from -0.3 to $-1.8 \mathrm{~W} \mathrm{~m}^{-2}$.

Sulfate particle is an important component of atmospheric aerosols. Many studies have discussed the importance of the sulfur cycle (Rodhe and Isaksen, 1980; Chin et al., 1996, 2000; Feichter et al., 1996; Koch et al., 2001; Iversen and Seland, 2002; Liao et al., 2003, Berglen et al., 2004). The key species in tropospheric sulfur cycle are the gaseous DMS (dimethylsufide) and $\mathrm{SO}_{2}$, and sulfate via their oxidation by various oxidants including $\mathrm{O}_{3}, \mathrm{OH}, \mathrm{H}_{2} \mathrm{O}_{2}, \mathrm{HO}_{2} \mathrm{NO}_{2}$ and $\mathrm{NO}_{3}$. Many chemical transport models (CTMs) have been developed to simulate the sulfur cycles using prescribed (offline) meteorology to drive the chemistry. Another approach has been to use prescribed aerosol for calculating radiative forcing in global climate models (e.g. Mitchell et al., 1995; Chou 2004; Chen and Penner 2005; Gu et al. 2006; Jones et al. 2007). Since interactions with the meteorological fields (e.g. cloud removal) are crucial to the sulfur cycle

Published by Copernicus Publications on behalf of the European Geosciences Union. 
evolution, and although such simulations do include the impact of aerosol radiative forcing on atmospheric circulation, the lack of consistency in considering non-linear in situ production of sulfate aerosols (Berglen et al., 2004) introduces large uncertainties in sulfur cycle estimates.

Many studies indicated that feedbacks might be more influential than expected (Kaufman and Freaser, 1997; Cerveny and Bailing, 1998; Audiffren et al., 2004; Resenfeld, 2000), therefore, models that do not include coupled chemistry, radiation and dynamics may have large errors in the estimates of the feedback mechanisms occurring in the climate system and impact the model results (Zhang, 2008). Recently, efforts have been devoted to the modeling of coupled climate-chemistry system in order to gain a better understanding of aerosol-cloud-climate interactions (Eyring et al., 2005; Jöckel et al., 2005). The impacts of coupling are still very uncertain, limited by the complexity of mechanisms considered in the model. For example, Mickley et al. (1999), considering only $\mathrm{O}_{3}$ impacts on radiation, estimated that the difference of $\mathrm{O}_{3}$ radiative forcing between offline and online calculations is about $2 \%$. Shindell et al. (2001) also used online model to illustrate that the $\mathrm{OH}$ concentration could be reduced by about $10 \%$, which would be significant to many chemical processes. Besides global models, regional models are also tending towards online coupling (e.g., Giorgi et al. 2002; Grell et al. 2005; Forkel and Knotche 2006; Huang et al. 2007), as the radiative effects can be particularly strong on the local scales.

In this study we incorporated an interactive tropospheric sulfur chemistry scheme into a global climate-chemistry model (GCCM) (Wong et al., 2004) to estimate radiative forcing of sulfate aerosols, including direct aerosol effect and aerosol-cloud albedo effect. Furthermore, by comparing simulations with and without the coupling of aerosol radiative forcing, we examined the meteorological responses to the forcing as well as feedbacks to the meteorology and subsequently to the aerosol fields.

\section{Description of the model and the simulations}

\subsection{The Global Climate-Chemistry Model}

The GCCM was developed by incorporating the University of Oslo tropospheric photochemical scheme (Isaksen and Hov, 1987; Berntsen and Isaksen, 1997) into the National Center for Atmospheric Research Community Climate Model (CCM3) with modification by the group of State University of New York at Albany (Wang et al., 1995; Wong and Wang, 2000, 2003). This model has been used for simulating tropospheric chemistry and the effect of ozone on radiation. In spite of cold biases of about 4-12 K in the polar regions, and small dry biases during July to August in Northern-hemispheric mid-latitudes, this model can reproduce reasonable inter-annual variability of the tropospheric

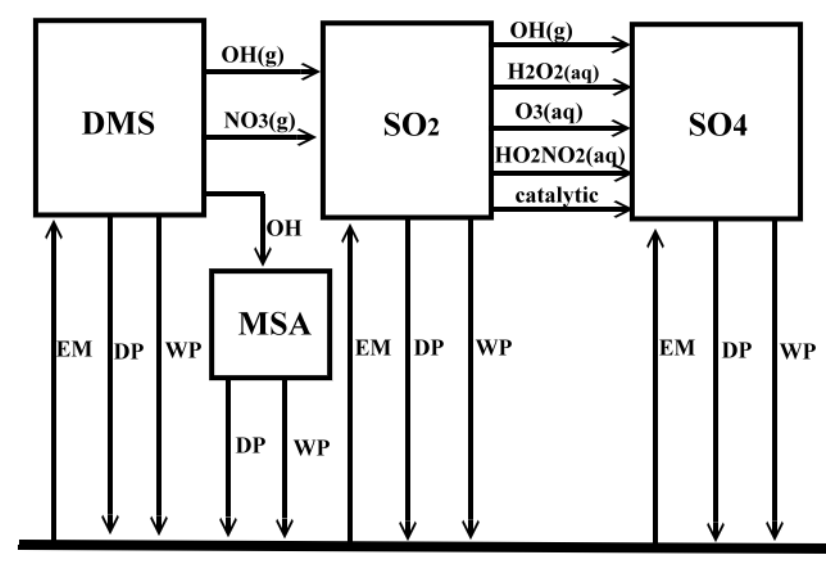

Fig. 1. Sulfur cycle in GCCM. Four species including DMS, MSA, $\mathrm{SO}_{2}$ and sulfate are included. The arrows are different fluxes including emission $(E M)$, dry deposition $(D P)$ and wet deposition (WP) and gas phase $(g)$ and aqueous phase $(\mathrm{aq})$ reactions.

system (Hack et al., 1998; Wong and Wang, 2003). However, in Wong et al. (2004) the sulfur chemistry that is important for the study of aerosol effects was not included because their focus was on ozone and its impact.

We have now incorporated the sulfur and oxidant chemistry scheme of Berglen et al. (2004) into GCCM, to take into account the interaction with the sulfate chemistry. Performing on-line calculations provide consistent estimates of chemical distribution and changes of gaseous- and aqueousphase compounds. Four new species, DMS, $\mathrm{SO}_{2}, \mathrm{MSA}$ and $\mathrm{SO}_{4}^{2-}$ (sulfate), are added. The new processes considered are: Emission of $\mathrm{SO}_{2}$, DMS and $\mathrm{SO}_{4}^{2-}$, dry and wet deposition of $\mathrm{SO}_{2}$, MSA and $\mathrm{SO}_{4}^{2-}$, and gaseous- and aqueousphase chemical reactions, as shown in the schematics of Fig. 1. The key gaseous and aqueous phase reactions for the sulfur cycle are listed in Table 1, and more details can be found in Berglen et al. (2004). Note that we did not consider the reaction of $\mathrm{OH}$ with dimethyl sulfoxide (DMSO) to form methane sulfinic acid, which further reacts with $\mathrm{OH}$ to form $\mathrm{SO}_{2}$ (Sørensen et al., 1996; Kukui et al. 2003). This simplification may lead to an underestimation of $\mathrm{SO}_{2}$ production from DMS. DMSO may be formed by photochemical or bacterial transformation from DMS (Liss and Galloway 1993), or produced intra-cellularly by phytoplankton (Simo, 2004). Unfortunately, the exact sizes of the source and sink of DMSO are not well known. Since the reaction rate constant for methane sulfinic acid to $\mathrm{SO}_{2}$ is of a similar order as that for DMS to $\mathrm{SO}_{2}$ (e.g., Kukui et al. 2003) and typically the limiting agent is $\mathrm{OH}$, our results should be orderof-magnitude correct. In addition, as we focused on anthropogenic sulfate, the error associated with this simplification tends to cancel out when the differences between simulations are taken. 
Table 1. Gaseous- and aqueous-phase reactions considered in the sulfur cycle.

\begin{tabular}{|c|c|}
\hline Reaction & Reaction rate constant \\
\hline \multicolumn{2}{|c|}{ Gas phase reaction $^{\mathrm{a}}$} \\
\hline $\begin{array}{l}\mathrm{DMS}+\mathrm{NO}_{3} \rightarrow \text { product } \rightarrow \mathrm{SO}_{2} \\
\mathrm{OH}+\mathrm{DMS} \rightarrow \mathrm{H}_{2} \mathrm{O}+\mathrm{CH}_{3} \mathrm{SCH}_{2} \rightarrow \mathrm{SO}_{2} \\
\mathrm{OH}+\mathrm{DMS} \rightarrow \mathrm{CH}_{3} \mathrm{~S}(\mathrm{OH}) \mathrm{CH}_{3} \rightarrow 0.75 \mathrm{SO}_{2} \\
+0.25 \mathrm{MSA}\end{array}$ & $\begin{array}{l}k=1.9 \times 10^{-13} \times \exp \left(\frac{520}{T}\right) \\
k=1.2 \times 10^{-11} \times \exp \left(\frac{-260}{T}\right) \\
k=\left(\left[\mathrm{O}_{2}\right] \times 1.7 \times 10^{-42} \times \exp \left(\frac{7810}{T}\right) /\right. \\
\quad\left(1+\left(\left[\mathrm{O}_{2}\right] \times 5.5 \times 10^{-31} \times \exp \left(\frac{7460}{T}\right)\right)\right)\end{array}$ \\
\hline $\mathrm{SO}_{2}+\mathrm{OH} \rightarrow \ldots \rightarrow \mathrm{H}_{2} \mathrm{SO}_{4}$ & $\begin{array}{l}k_{\mathrm{OH}}=\left(\frac{k_{0}}{1+\frac{k_{0}}{k_{\infty}}}\right) \times 0.6\left\{1+\left[\log \left(k_{0} / k_{\infty}\right)\right]^{2}\right\}-1 \\
k_{0}=3.0 \times 10^{-31} \times\left(\frac{300}{T}\right)^{3.3} \times[M] \\
k_{\infty}=1.5 \times 10^{-12}\end{array}$ \\
\hline \multicolumn{2}{|c|}{ Aqueous phase reaction } \\
\hline $\begin{array}{l}\mathrm{H}_{2} \mathrm{O}_{2}(\mathrm{aq})+\mathrm{HSO}_{3}^{-}(\mathrm{aq}) \rightarrow \mathrm{H}^{+}(\mathrm{aq})+\mathrm{SO}_{4}^{2-}(\mathrm{aq}) \\
+\mathrm{H}_{2} \mathrm{O}\end{array}$ & $k_{\mathrm{H}_{2} \mathrm{O}_{2}}=\frac{8.0 \times 10^{4} \times \exp \left(-3650 \times T_{f}\right)}{0.1+\left[H^{+}\right]}$ \\
\hline $\mathrm{O}_{3}(\mathrm{aq})+\mathrm{SO}_{3}^{2-}(\mathrm{aq}) \rightarrow \mathrm{SO}_{4}^{2-}(\mathrm{aq})+\mathrm{O}_{2}(\mathrm{aq})$ & $k_{\mathrm{O}_{3}}=1.8 \times 10^{4} \times\left[H^{+}\right]^{-0.4^{c}}$ \\
\hline $\begin{array}{l}\mathrm{HO}_{2} \mathrm{NO}_{2}(\mathrm{aq})+\mathrm{HSO}_{3}^{-}(\mathrm{aq}) \rightarrow 2 \mathrm{H}^{+}(\mathrm{aq}) \\
+\mathrm{SO}_{4}^{2-}(\mathrm{aq})+\mathrm{NO}_{3}^{-}\end{array}$ & $k_{\mathrm{HO}_{2} \mathrm{NO}_{2}}=3.1 \times 10^{5^{\mathrm{d}}}$ \\
\hline
\end{tabular}

$T$ : Temperature, $T_{f}=1 / T-1 / 298,[M]$ : concentration of air molecules, $\left[H^{+}\right]$: concentration of hydronium ions, assumed as $3.16 \times 10^{-5} \mathrm{~mol} / \mathrm{L}$ (i.e., $\mathrm{pH}=4.5$ ).

${ }^{a}$ rates are from De More et al. (1997)

b unit is L/mol/sec, from Martin and Damschen (1976)

c unit is $\mathrm{L} / \mathrm{mol} / \mathrm{sec}$, from Moller (1980).

d unit is $\mathrm{L} / \mathrm{mol} / \mathrm{sec}$, from Amels et al. (1996)

Table 2. $\mathrm{SO}_{2}$ global emissions used in GCCM.

\begin{tabular}{cr}
\hline Type & Strength, $\mathrm{Tg} \mathrm{S} \mathrm{yr}^{-1}$ \\
\hline \multirow{2}{*}{ 1985GEIA emission $\quad>100 \mathrm{~m}$} & 42.94 \\
Biomass burning emission & 24.03 \\
Ship emission & 2.24 \\
Volcanic emission & 3.41 \\
& 8 \\
\hline
\end{tabular}

Also note that sea-surface temperatures in GCCM are specified according to the results from the Atmospheric Model Intercomparison Project 2 (Gates et al., 1999). Using specified sea-surface temperatures tends to limit the climate responses. On the other hand, without the convoluted ocean feedbacks, the relationship between sulfate forcing and climate response can be discussed more clearly.

\subsection{Emissions}

The global emissions of pollutants except sulfur species are based on IPCC 2001 (OxComp Y2001), with annual mean values rescaled to 1990 emission following Wong et al. (2004). Sulfur emissions include anthropogenic emission sources following the GEIA 1985 inventory (Benkovitz et al., 1996), ship emission from Endresen et al. (2003), biomass burning from Spiro et al. (1992) and Graft et al. (1997). Table 2 shows the total emission strengths from each source. It is assumed that $5 \%$ of anthropogenic sulfur is emitted as sulfates while the rest as $\mathrm{SO}_{2}$ (Langner and Rodhe 1991).

Natural sulfur sources include volcanic emission (Spiro et al., 1992) and DMS emission from the ocean (Kettle et al., 1999; Kettle and Andreae, 2000). The DMS flux is calculated with specified seawater DMS concentrations using transport parameterization of Liss and Merlivat (1986):

$F=V_{k} \times\left(C_{\mathrm{DMS}, \text { air }} / H-C_{\mathrm{DMS}, \text { ocean }}\right)$

where $V_{k}$ is parameterized transport velocity, $C_{\mathrm{DMS} \text {, air }}$ is DMS concentration in air, $H$ is Henry constant for DMS, and $C_{\text {DMS,ocean }}$ is DMS concentration in seawater. The amount of $\mathrm{SO}_{2}$ produced from DMS conversion stays in a narrow range of 22.4 to $23.4 \mathrm{Tg} \mathrm{S}$ (terra grams of sulfur) per year among all simulations conducted in this study (based on the assumptions made for the products in Reaction (R3) in Table 1). 


\subsection{Cloud effective radius}

As mentioned in previous sections, the sulfate particles could serve as cloud condensation nuclei and modify cloud drop number concentration hence cloud radiative properties, leading to the cloud albedo effect. However, similar to that done in many other GCMs, the previous version of GCCM applies prescribed cloud droplet effective radii of $5 \mu \mathrm{m}$ over continents and $10 \mu \mathrm{m}$ over oceans for the radiation calculation. Such an approach only grossly represents the spatial distribution of aerosol influences and certainly cannot reflect response to the change of aerosols.

Based on observations, Boucher and Lohmann (1995) provided improvement with empirical formulas that link the effective radii of cloud drops to sulfate mass loading:

$N_{C}=\exp \left(a_{0}+a_{1} \cdot \log \left(M_{\mathrm{SO}_{4}}\right)\right)$

where $M_{\mathrm{SO}_{4}}$ is the sulfate mass loading in $\mu \mathrm{g} \mathrm{m}^{-3}$ and $N_{C}$ is the cloud droplet number concentration in $\mathrm{cm}^{-3}$, and different values of coefficients $a_{0}$ and $a_{1}$ are provided for the continental and oceanic conditions. The effective radius $r_{e}$ then can be calculated as:

$r_{e}=\left(\frac{3 w_{l}}{4 \pi \rho_{w} k N_{C}}\right)^{1 / 3}$

where $w_{l}$ is cloud water content, $\rho_{w}$ is the density of water, and $k$ is a modification coefficient to account for the difference between the mean volume radius $\left(r_{v}\right)$ and $r_{e}$ of cloud droplets, which is assumed as 0.67 over continents and 0.8 over oceans according to Martin et al. (1994). However, the formulas of Boucher and Lohmann (1995) tend to overestimate the number concentration of cloud drops, thus underestimate the effective radii, especially over the oceans. That will lead to overestimated sulfate radiative forcing. Quaas and Boucher (2005) made an adjustment to correct for this underestimate and provided the coefficients $a_{0}=3.9$ and $a_{1}=0.2$, and these are the values adopted for this study. The coefficients given by Boucher and Lohmann (1995) will also be tested and presented in the discussion section.

\subsection{Simulations}

Two sets of simulations are conducted to estimate the sulfate aerosols direct and indirect effects. Simulations N0, N1 and $\mathrm{N} 2$ apply only natural sulfur emissions (i.e. DMS and volcanic $\mathrm{SO}_{2}$ ), whereas simulations $\mathrm{A} 0, \mathrm{~A} 1$ and $\mathrm{A} 2$ take additional anthropogenic sulfur emissions. To focus on the sulfate effect, the emissions of other chemical species are kept the same for all simulations (following the 1985 scenario) so that their photochemistry is comparable except when the sulfur species is involved. So, in the following discussions the term "natural condition" refers to natural sulfate, not the whole chemistry. The degree of coupling the aerosol effects is indicated by the numbers after " $N$ " and " $A$ ", where ' 0 ' denotes no sulfate radiative effects, ' 1 ' denotes only sulfate di- rect effect, and " 2 " indicates both sulfate direct effect and the first indirect effect.

Six months' spin-up were conducted for NO, and then used to run other cases for a period of 13 years. For analysis, we used results from the last 10 years. Monthly meteorological fields and trace gas concentrations were examined to ensure that near-steady-state climate conditions are reached. Note that a 10-year simulation might be too short, and we did not perform ensemble runs, so our results are still tentative and should be used with caution. All simulations apply a horizontal resolution of T42 (equivalent to $2.8^{\circ} \times 2.8^{\circ}$ ) and 18 vertical layers from the surface to about $2.5 \mathrm{hPa}$. The time step used is $20 \mathrm{~min}$, with the exception that shortwave and long-wave radiation processes are calculated hourly.

\section{Analyses}

In the following we first briefly compare the global distribution of simulated meteorological fields and sulfur species with observational data to check the general model performance using results from the A2 and N2 simulations. Then, the budgets of sulfur cycle are analyzed to facilitate subsequent discussions on sulfate aerosol forcing and responses.

\subsection{Global distributions}

As a first step of verifying GCCM performance, we compared the meteorological fields from the A2 simulation to those of the climatological data. Near-surface mean temperature and wind fields are compared with the 19792005 climatology of the NCEP-DOE Reanalysis 2 (NCEP RE2), whereas surface precipitation is compared with that of the Global Precipitation Climatology Project (GPCP, 1979present). Figure $2 \mathrm{a}-\mathrm{d}$ show the convergence over tropical regions, divergence over $30^{\circ} \mathrm{N}$ and $30^{\circ} \mathrm{S}$ and the distribution of isotherms of A2 results are similar to NCEP RE2 climatology. The general patterns of surface precipitation simulated with GCCM resemble those of GPCP, except that the model result is wetter over the tropics and drier over mid-latitude Pacific Ocean (Fig. 2e-f). Since the model sea surface temperature is prescribed, air temperature above the ocean is close to the climatology.

Figure $3 \mathrm{c}$ shows the simulated global distribution of $\mathrm{SO}_{2}$ column concentration from simulation A2. Evidently, areas of high concentrations occur near or downwind of major anthropogenic emission hot spots in Central Europe, Eastern North America, East Asia, and Russia. There are also secondary maxima in Southern Africa, South America and Indonesia due to biomass burning and volcanic eruptions. These patterns are in general agreement with GOME satellite observation reported in Khokhor et al. (2004). Differences exist in a few places, partly because the 1985 distribution is for a different time period than the GOME observations, for which data are available only after 1995. Besides 
(a)

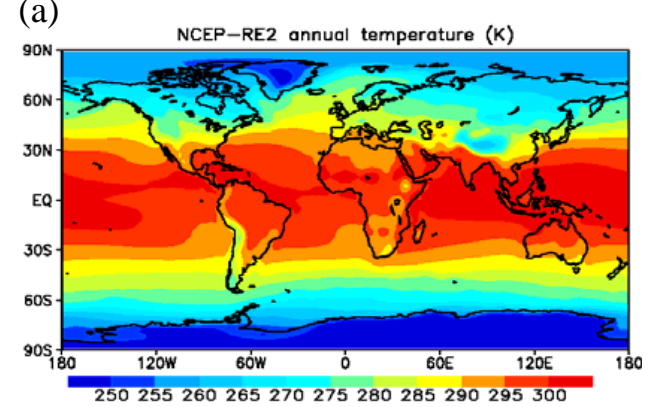

(c)

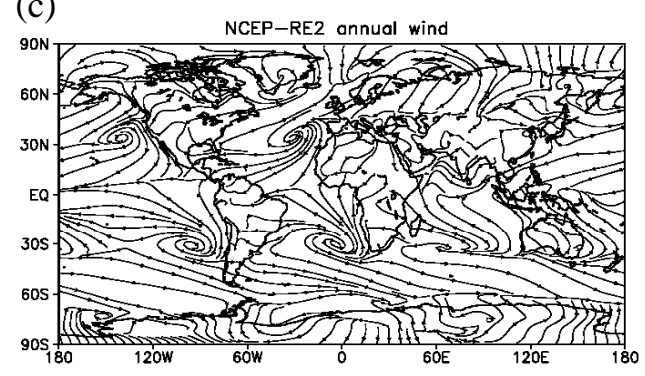

(e)

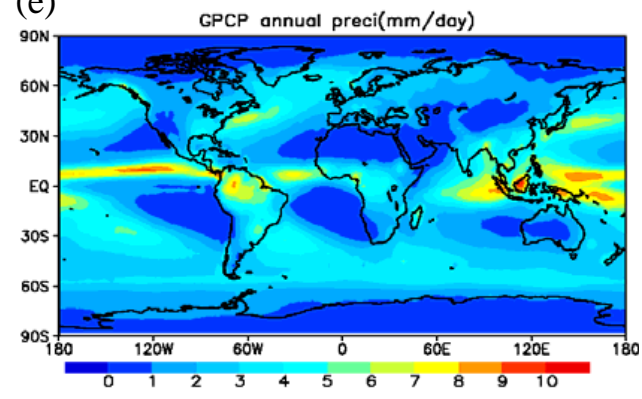

(b)

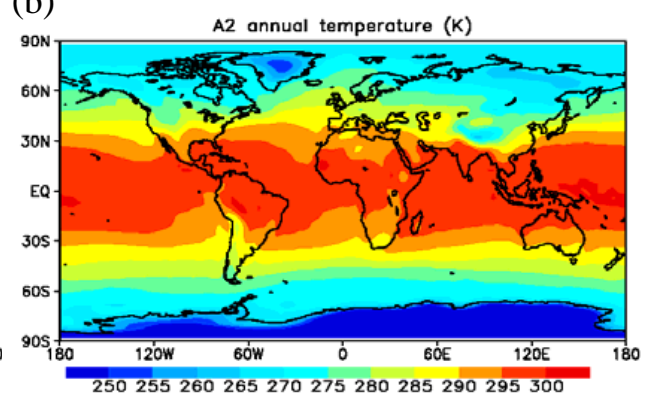

(d)

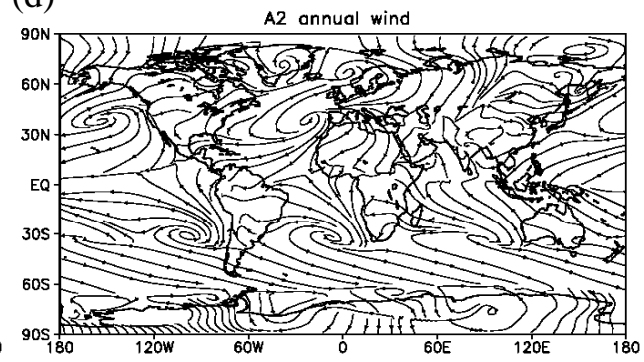

(f)

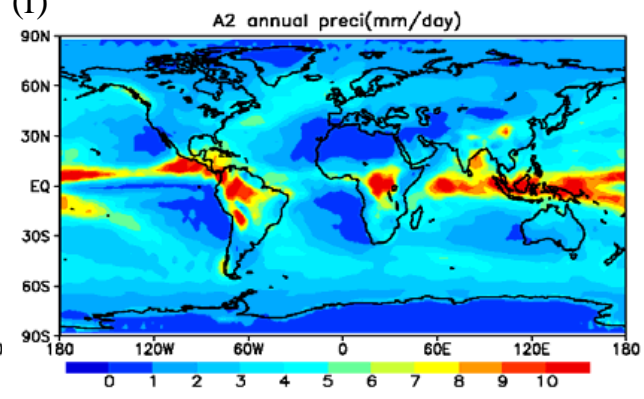

Fig. 2. Comparison of meteorological fields from the A2 simulation (right panels) with those from observation or reanalysis data (left panels). Top: near surface temperature (K); Middle: near-surface streamline; Bottom: precipitation (in mm day ${ }^{-1}$ ).

the differences in anthropogenic emission inventory, the discrepancies may also result from the use of climatological volcanic emissions in our simulations, which might not reflect major volcanic eruptions during 1996-2002 (Khokhor et al. 2004). Nevertheless, the GCCM simulation captured the general features of $\mathrm{SO}_{2}$ spatial distribution.

The sulfate distributed has a rather similar pattern as $\mathrm{SO}_{2}$ (Fig. 3d), except that it spreads over a wider area, likely due to time lag of chemical conversion from $\mathrm{SO}_{2}$ which allows more time for atmospheric dispersion, since it is a secondary compound, while $\mathrm{SO}_{2}$ is a primary compound with shorter lifetime (Berglen et al., 2004). Unfortunately, the simulated global distribution of sulfate is difficult to verify, as relevant observation is scarce. Satellite observations of aerosol optical depth seem to be pertinent, but they contain contribution from non-sulfate particles such as mineral dust and soot particles, so their global features can be distinctly different from the sulfate distribution. Nevertheless, we can get a partial verification with the non-sea-salt sulfate data provided by Saltzman et al. (1986) which were measured at remote is- lands in the north Pacific (during 1981-1982) and south Pacific (during 1983-1984). The annual means from GCCM are on the whole lower than the observed concentrations at these stations, with differences ranging from $12 \%$ to $48 \%$. Such underestimations could be related to many deficiencies in GCCM, such as the omission of DMSO which may contribute significantly to the production of $\mathrm{SO}_{2}$ and hence sulfate over the remote oceans. Nonetheless, the discrepancy between model and observation is generally less than the standard deviation of the observed values. Another way to check the correctness of our sulfur-cycle calculations is to compare with results from other models that also applied the 1985 emission inventory. Global model studies referred to in Berglen et al. (2004) and in the AeroCom project (Schulz et al. 2006) revealed large differences in current estimates of sulfate burden. The mean global loading of $\mathrm{SO}_{2}$ and sulfate from our A2 simulation are 0.47 and $0.33 \mathrm{Tg} \mathrm{S}$, respectively, and the value for sulfate is considerably lower than other results listed in Table 3 and on the low side of those shown in Fig. 5. Note that the sulfur scheme used in GCCM is 
(a)

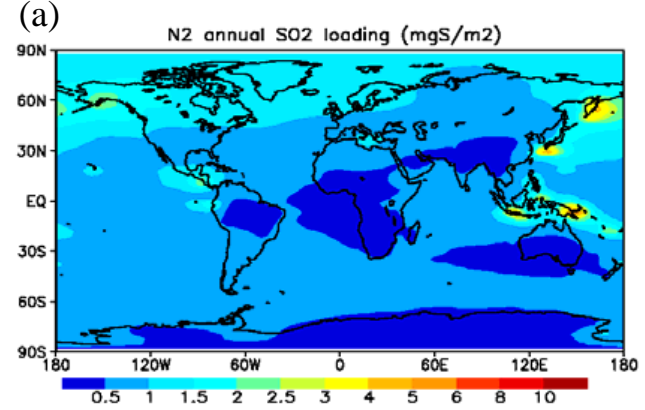

(c)

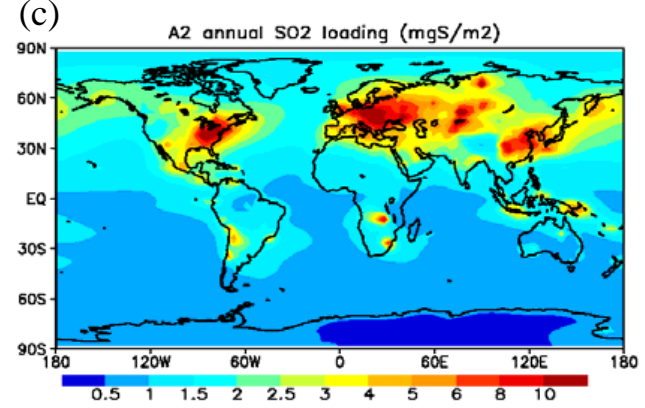

(e)

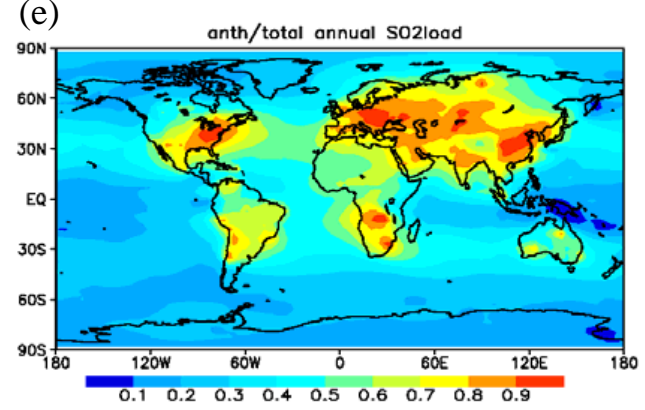

(g)

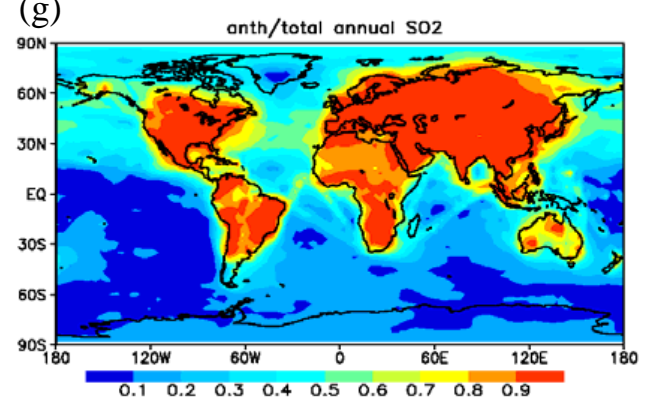

(b)

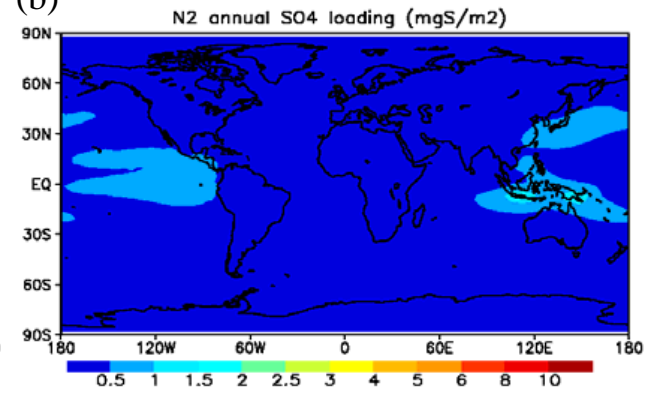

(d)

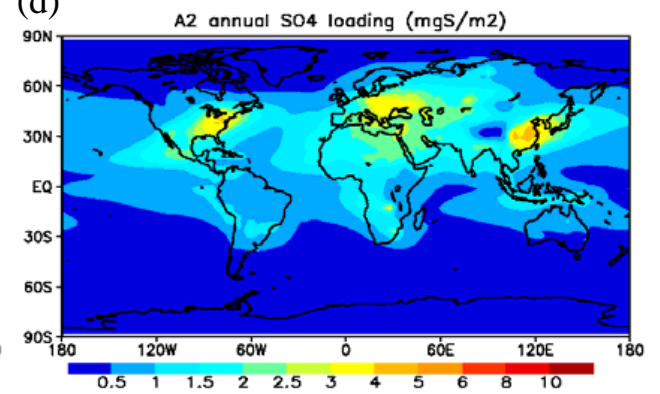

(f)

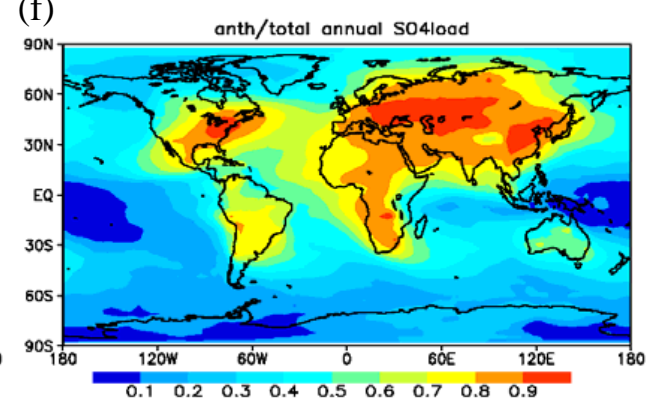

(h)

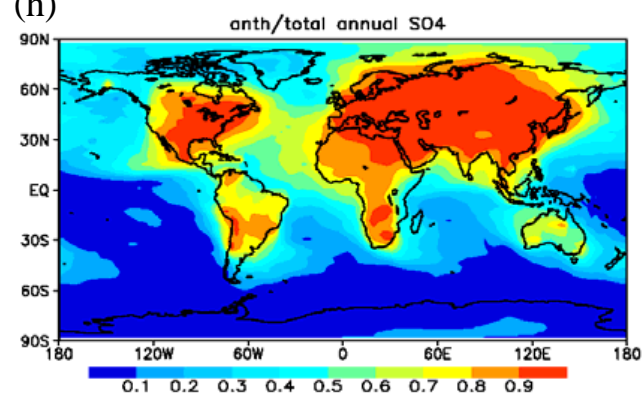

Fig. 3. Comparison of the global distribution of $\mathrm{SO}_{2}$ (left) and sulfate (right) from GCCM simulations. Top row: column loading (in $\mathrm{mg} \mathrm{S}$ $\mathrm{m}^{-2}$ ) from the N2 simulation; Second row: column loading (in $\mathrm{m} \mathrm{S} \mathrm{m}^{-2}$ ) from the A2 simulation; Third row: ratio of anthropogenic to total (A2-N2:A2) column loading; Bottom row: ratio of anthropogenic to total (A2-N2:A2) concentration near the surface.

essentially the same as that in Berglen et al. (2004), but in our calculations the aqueous-phase reactions are not allowed to occur in cloud ice. When reactions in cloud ice are turned on, our $\mathrm{SO}_{2}$ and sulfate loadings are very close to theirs.

In the following, we analyze the contribution of sulfur species from different emission sources and the production mechanisms of sulfate. The natural $\mathrm{SO}_{2}$ concentrated over the northern high latitudes and tropical regions to the east of
Indonesia (Fig. 3a) are mainly from volcanic emissions. Annual global production of $\mathrm{SO}_{2}$ from DMS is about $23 \mathrm{Tg} \mathrm{S}$, much higher than the $8 \mathrm{TgS}$ per year from volcanic emissions (Table 2). However, DMS is released in the lower troposphere, so the $\mathrm{SO}_{2}$ formed from DMS may experience stronger surface removal by dry deposition or conversion to sulfate by aqueous-phase reactions where liquid clouds are prevalent. Volcanic emission is actually a more dominant 
Table 3. Global sulfur burden (in $\mathrm{Tg} \mathrm{S}$ ) calculated from different sets of GCCM simulations and comparison with those from a few models that also applied the 1985 GEIA emission inventory.

\begin{tabular}{llllllllllll}
\hline & $\mathrm{N} 0$ & $\mathrm{~N} 1$ & $\mathrm{~N} 2$ & $\mathrm{~A} 0$ & $\mathrm{~A} 1$ & $\mathrm{~A} 2$ & $\mathrm{a}$ & $\mathrm{b}$ & $\mathrm{c}$ & $\mathrm{d}$ & $\mathrm{e}$ \\
\hline $\mathrm{SO}_{2}$ & 0.158 & 0.156 & 0.157 & 0.466 & 0.459 & 0.466 & 0.26 & 0.34 & 0.42 & 0.56 & 0.61 \\
sulfate & 0.103 & 0.103 & 0.104 & 0.330 & 0.325 & 0.326 & 0.50 & 0.53 & 0.62 & 0.73 & 0.96 \\
\hline
\end{tabular}

a: Berglen et al. (2004); b: Chin et al. (1996); c: Restad et al. (1998); d: Koch et al. (1999); e: Roelofs et al. (1998).

(a)

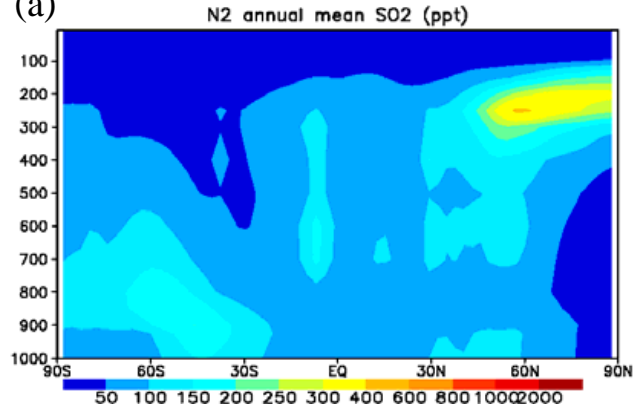

(c)

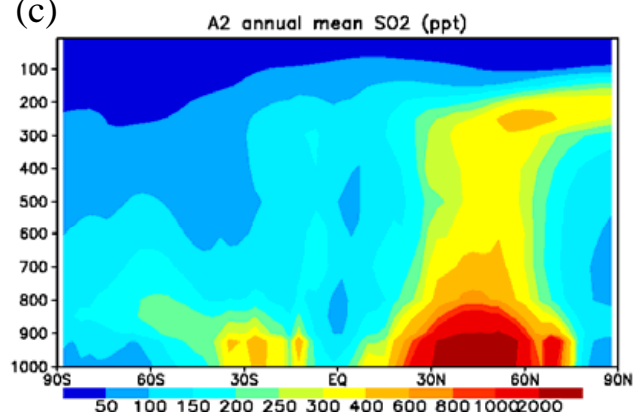

(e)

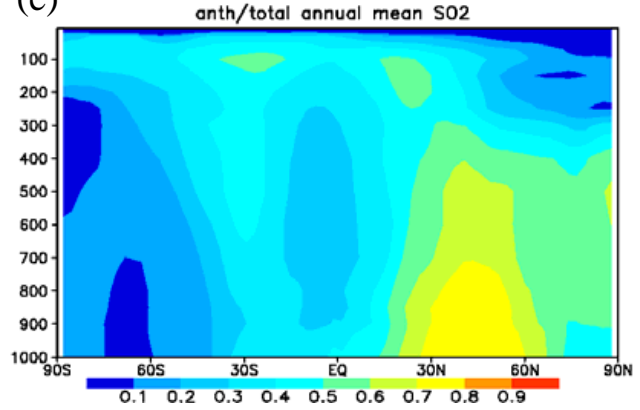

(b) N2 annual mean $504(\mathrm{ppt})$

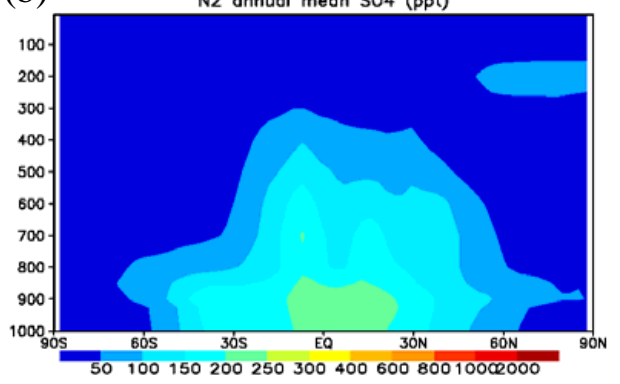

(d)

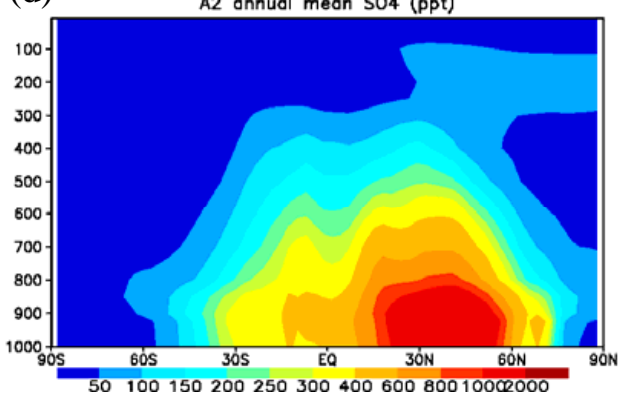

(f)

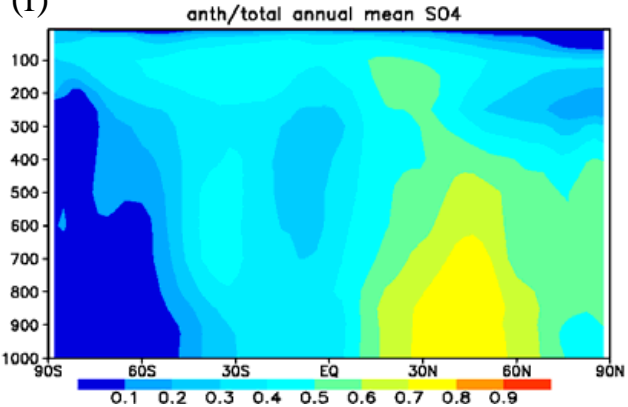

Fig. 4. Comparison of the vertical profiles of zonal-mean $\mathrm{SO}_{2}$ (left) and sulfate (right) concentrations. Top: concentration (in parts per trillion by volume; ppt) under natural conditions (N2); Middle: concentration (in ppt) under polluted conditions (A2); Bottom: ratio of anthropogenic to total (A2-N2:A2) concentrations.

source of net global $\mathrm{SO}_{2}$, typically injected into the upper troposphere (Fig. 4a). Thus, the global distribution of column $\mathrm{SO}_{2}$ in Fig. 3a does not show obvious signature of DMS production zones but rather concentrate over the volcanic active areas.
Natural sulfate also spreads over a much wider area than $\mathrm{SO}_{2}$ distribution both horizontally (Fig. 3b) and vertically (Fig. 4b). From Fig. 3e one can see that anthropogenic sources dominate $\mathrm{SO}_{2}$ over all the populated continents and adjacent oceans. The situation for sulfate (Fig. 3f) is generally similar, with natural contributions dominating only over the polar regions and some remote oceans. Figure $3 \mathrm{~g}$ shows 


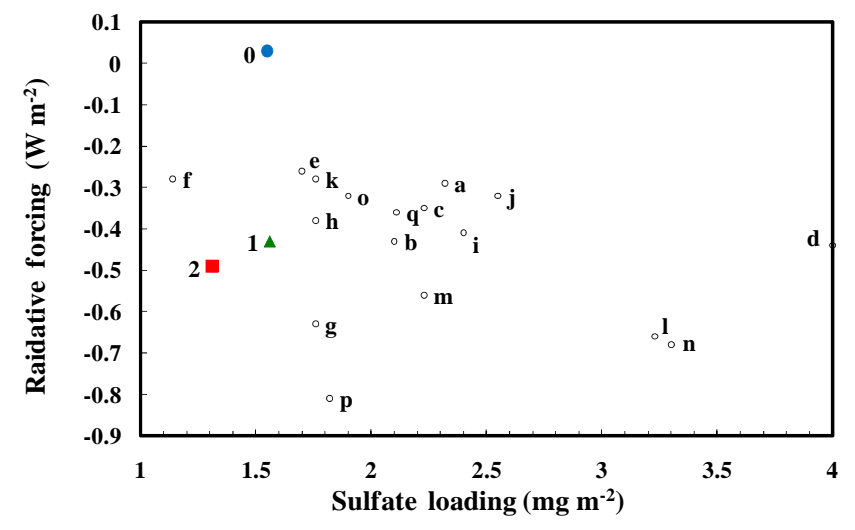

Fig. 5. Comparison of sulfate burden and direct effect between GCCM and other model results. The filled circle, triangle and square represent the GCCM results of A0-N0 (blue circle labeled " 0 "), A1-N1 (green triangle labeled "1") and A2-N2 (red square labeled "2"), respectively. The letters next to the open circles indicate results from the following studies: (a) Boucher and Anderson (1995), (b) Chuang et al. (1997), (c) Feichter et al. (1997), (d) Ghan et al. (2001a), (e) Graf et al. (1997), (f) Hansen et al. (1998), (g) Haywood and Ramaswamy (1998), (h) Haywood et al. (1997a), (i) Iversen et al. (2000), (j) Jacobson (2001), (k) Kiehl and Briegleb (1993), (l) Kiehl and Rodhe (1995), (m) Kiehl et al. (2000), (n) Koch et al. (1999), (o) Myhre et al. (1998c), (p) Penner et al. (1998b), (q) van Dorland et al. (1997).

an even sharper contrast of anthropogenic versus natural $\mathrm{SO}_{2}$ at the surface layer. Over most of the continents, more than $90 \%$ of surface $\mathrm{SO}_{2}$ is of anthropogenic origin. Over the remote oceans one can also see the dominance of anthropogenic emissions on $\mathrm{SO}_{2}$ concentration over major shipping routes, but this feature smears out for surface sulfate due to the time-lag in $\mathrm{SO}_{2}$ to sulfate conversion thus more time for atmospheric dispersion.

The zonal mean vertical distribution of sulfur in Fig. 4 shows that natural $\mathrm{SO}_{2}$ is concentrated in the upper and middle troposphere, reflecting their dominant source from volcanic activities; whereas natural sulfate is higher in the lower troposphere, particularly over the tropics, where in-cloud conversion from $\mathrm{SO}_{2}$ is most active. Anthropogenic $\mathrm{SO}_{2}$ concentration is the highest near the surface of mid-latitude Northern Hemisphere (Fig. 4c), and a secondary maximum can be found near the surface around $30^{\circ} \mathrm{S}$, both over regions with strong anthropogenic influences. Anthropogenic sulfate has a similar pattern, except that the secondary maximum in the Southern Hemisphere becomes less obvious due to transport. The fractions of anthropogenic $\mathrm{SO}_{2}$ and sulfate in the Southern Hemisphere remain mostly below 50\%. Over the Northern Hemisphere, the fraction may exceed $70 \%$ in the mid-latitude lower troposphere, and the 50\% isopleths may well reach the 300-hPa level.

\subsection{Sulfur cycle}

The net sulfate loading is determined by the rates of production (direct emission and oxidation from $\mathrm{SO}_{2}$ in air and clouds) and removal (dry and wet deposition). Conversion of $\mathrm{SO}_{2}$ into sulfate occurs mainly in clouds. For natural conditions, $60 \%$ of the total conversion are from $\mathrm{H}_{2} \mathrm{O}_{2}$ oxidation and $4 \%$ are from ozone oxidation, whereas gas-phase oxidation by $\mathrm{OH}$ radical accounts for about $26 \%$, and the rest is by other in-cloud reactions. With the addition of anthropogenic emissions (A2), the proportions become $52 \%$ by $\mathrm{H}_{2} \mathrm{O}_{2}, 10 \%$ by ozone and $24 \%$ by $\mathrm{OH}$. Such a change of proportions implies that $\mathrm{H}_{2} \mathrm{O}_{2}$ and $\mathrm{OH}$ are probably the predominant limiting agents in the oxidation reactions. The fraction of in-cloud sulfate production from our A2 results (76\%) is near the median of values from several global CTMs that ranging from 64 to $85 \%$ (e.g. Chin et al., 1996; Restad et al., 1998; Roelofs et al., 1998; Koch et al., 1999, Chin et al. 2000; Berglen et al. 2004). Under natural conditions, the removal of sulfate from the atmosphere is mainly via wet deposition, and only $11 \%$ is by dry deposition; whereas the removal of $\mathrm{SO}_{2}$ is $92 \%$ by dry deposition. For polluted conditions, the proportion by dry deposition increased slightly to $12 \%$ for sulfate and $95 \%$ for $\mathrm{SO}_{2}$. As most of the anthropogenic sulfur is emitted close to the surface, it is thus more susceptible to dry deposition. Globally, anthropogenic emissions (from A2-N2) are responsible for $66 \%$ of $\mathrm{SO}_{2}$ and $68 \%$ of sulfate loadings (see Table 3). These ratios are close to the anthropogenic fraction $(70 \%)$ of $\mathrm{SO}_{2}$ emission.

Dividing the global loading given in Table 3 by the overall rate of destruction (same as rate of production under steady state), we are able to estimate the lifetime of $\mathrm{SO}_{2}$ to be 1.7 days under polluted conditions (A2). For comparison, the $\mathrm{SO}_{2}$ lifetime under polluted conditions are 1.1, 1.3, 2.0, 2.6 and 2.4 days in Berglen et al. (2004), Chin et al. (1996), Restad et al. (1998), Koch et al. (1999) and Roelofs et al. (1998), respectively. The lifetime of sulfate is estimated to be 2.0 days for the polluted (A2) conditions, and this value is lower than those from the aforementioned CTM calculations, which range from 3.7 to 5.7 days. The overall lifetime of sulfur ( $\mathrm{SO}_{2}$ plus sulfate) is 2.9 days in $\mathrm{A} 2$. The lifetimes of "natural" sulfur are somewhat longer, but the values are actually not very meaningful because the chemistry in the $\mathrm{N}$-series simulations is still under the influence of other anthropogenic emissions.

The atmospheric lifetime is determined mainly by its largest sink, so for $\mathrm{SO}_{2}$ the dominating factor is in-cloud oxidation, while for sulfate wet deposition is the most important. The large variation of sulfur lifetime among models shown above indicates high uncertainties in the simulation of sulfur cycle, and the uncertainties are mainly a result of differences in formulating cloud-related sink processes. It is also possible that the amount of cloud water (for the oxidation to take place) could be quite different among models. Apparently, different climate models, even with prognostic clouds, 
Table 4. Differences of global-mean radiative forcing (in $\mathrm{W} \mathrm{m}^{-2}$ ) between simulations at the surface and top of atmosphere (TOA) under both clear-sky and all-sky conditions. Statistical significance under a two tailed test on the monthly values is indicated with the symbols "*”" and "\#” for reaching the $95 \%$ and $80 \%$ confidence levels, respectively.

\begin{tabular}{lrc}
\hline & Clear sky & All sky \\
\hline A0-N0 & 0.03 & 0.03 \\
A1-N1 & $-0.43 \#$ & $-0.24 \#$ \\
A2-N2 & $-0.49^{*}$ & $-1.85^{*}$ \\
N1-N0 & $-0.14^{*}$ & $-0.39^{*}$ \\
A1-A0 & $-0.60^{*}$ & $-0.66^{*}$ \\
N2-N0 & $0.05^{*}$ & $-7.91^{*}$ \\
A2-A0 & $-0.48^{*}$ & $-9.78^{*}$ \\
\hline
\end{tabular}

cannot get consistent cloud water and precipitation (cf. Lau et al., 1996). Furthermore, the shorter sulfate lifetime in our model could also due to a stronger precipitation which leads to stronger wet deposition. Again, precipitation among climate models are very different, and the value $\left(3.2 \mathrm{~mm} \mathrm{day}^{-1}\right)$ obtained in GCCM is on the high side comparing to various GCM results from AMIP (Lau et al., 1996).

\subsection{Sulfate radiative forcing}

In this section we present the direct effect and the first indirect effect of sulfate aerosol forcing. To determine radiative forcing from anthropogenic sulfate aerosols, we simply take the difference between the A-series and N-series calculations. The distribution of radiative forcing at the surface is very similar to the distribution at the top of the atmosphere (TOA), only the latter is therefore discussed. Note that sulfate in $\mathrm{A} 0$ and $\mathrm{N} 0$ does not affect radiation, so the differences of radiative forcing between these two simulations arise from the influences of ozone chemistry and from model internal variability, which will be further elaborated later.

Globally, as shown in Table 4, direct forcing of anthropogenic sulfate from $\mathrm{A} 1-\mathrm{N} 1$ is $-0.43 \mathrm{~W} \mathrm{~m}^{-2}$, which is much more significant than the $0.03 \mathrm{~W} \mathrm{~m}^{-2}$ by ozone chemistry from the A0-N0 results. The direct forcing is a bit stronger $\left(-0.49 \mathrm{~W} \mathrm{~m}^{-2}\right)$ in the fully coupled simulations (A2-N2). Figure 5 compares the mass loading and direct forcing of sulfate from various models. Our sulfate mass loading is on the low side within the range of others, whereas our direct forcing from $\mathrm{A} 1-\mathrm{N} 1$ or $\mathrm{A} 2-\mathrm{N} 2$ is close to the median value. Direct forcing under all-sky conditions may be represented by the A1-N1 forcing, as neither A1 nor N1 considered the sulfate indirect effect. From Table 4 we can see that the global direct forcing reduces to $-0.24 \mathrm{~W} \mathrm{~m}^{-2}$ when considering the effect of cloud masking (i.e. under all sky conditions).

The indirect forcing of anthropogenic sulfate may be represented by the differences between the A2 and N2 results.

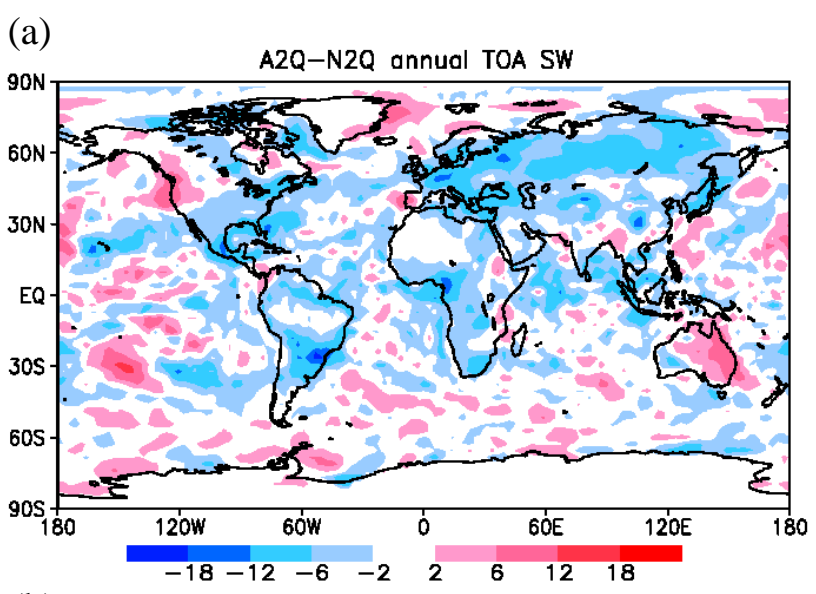

(b)

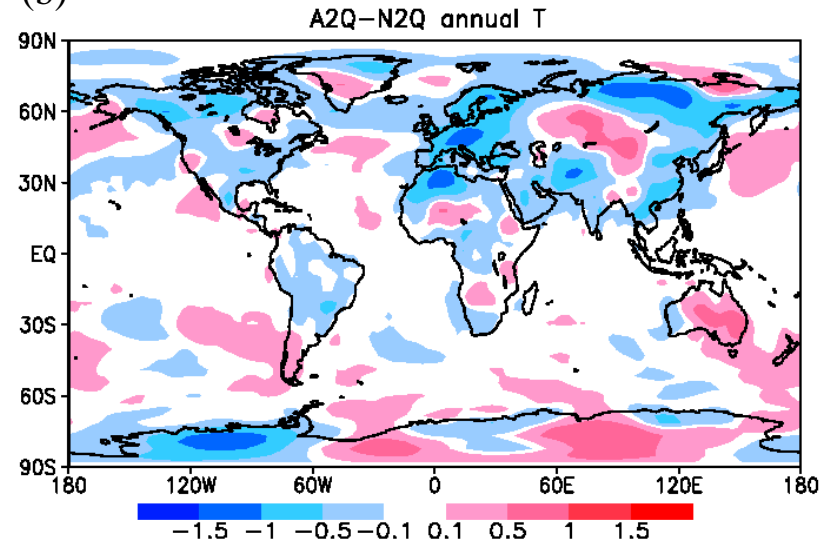

Fig. 6. Anthropogenic sulfate forcing and climate response from the A2-N2 results. Top: radiative forcing at TOA (in $\mathrm{W} \mathrm{m}^{-2}$ ). Bottom: near-surface air temperature change (in $\mathrm{K}$ ).

Note that, because the cloud effective radii are prescribed in $\mathrm{A} 0, \mathrm{~A} 1, \mathrm{~N} 0$ and $\mathrm{N} 1$ simulations, it is not appropriate to use A2-A0 or N2-N0 to represent the indirect effect of sulfate. As the global indirect forcing of is much higher than the direct forcing, one may regard it as primarily from the indirect effect. Figure 6a shows the distribution of total sulfate forcing based on A2-N2 results. The indirect forcing not only is strong over the polluted areas but also extends to areas that are quite far away, such as a large portion of the Atlantic and significant portion of other oceans. The highest regional indirect forcing may exceed $-20 \mathrm{~W} \mathrm{~m}^{-2}$ over eastern North America and southeastern China. But there are also areas experiencing positive forcing, mostly over the continents around the regions of strong negative forcing, likely resulting from regional adjustment in the dynamics and cloud fields. These positive forcings lead to a smaller global indirect forcing that averages to about $-1.85 \mathrm{~W} \mathrm{~m}^{-2}$. Alternative estimation can be derived from (A2-A0)-(N2-N0) forcing for all-sky conditions, which gives a global indirect forcing of $-1.87 \mathrm{~W} \mathrm{~m}^{-2}$. This value is not too far from that of the A2-N2 results, indicating the robustness of its value. 
Table 5. Simulated meteorological responses to sulfate radiative forcing over the globe. The symbols representing statistical confidence level are the same as in Table 4. Also listed at the bottom are simulated total cloud coverage and precipitation as a reference for comparison.

\begin{tabular}{lcrr}
\hline & Temperature change $(\mathrm{K})$ & Cloud fraction change & Precipitation change ratio \\
\hline A0-N0 & 0.03 & -0.0002 & $-0.17 \%$ \\
A1-N1 & 0.02 & 0.0014 & $-0.06 \%$ \\
A2-N2 & $-0.08^{*}$ & 0.0012 & $-0.08 \%$ \\
N1-N0 & 0.003 & -0.0014 & $-0.14 \%$ \\
A1-A0 & 0.008 & $0.0027^{*}$ & $-0.03 \%$ \\
N2-N0 & 0.20 & -0.0036 & $0.83 \%$ \\
A2-A0 & $0.09^{*}$ & $-0.0026^{*}$ & $0.91 \% \%^{*}$ \\
\hline Cloud fraction & A0 & 0.602 & \\
& A1 & 0.605 & \\
& A2 & 0.600 & \\
\hline Precipitation (mm/day) & A0 & 3.155 & \\
& A1 & 3.154 & \\
& A2 & 3.183 & \\
\hline
\end{tabular}

To provide a broader perspective, we compare our model results with other studies, noting that there are many differences among the models. IPCC (2007) summarized results from different estimations and suggested the range of -0.1 to $-0.9 \mathrm{~W} \mathrm{~m}^{-2}$ for the direct effect, and -0.3 to $-1.8 \mathrm{~W} \mathrm{~m}^{-2}$ for the first indirect effect. Our estimation of the direct effect is within the range while the indirect effect is on the high end. The difference between the results of GCCM and other models might be due to the diversity of process treatments as discussed in AERO COM intercomparison (Textor et al., 2006). The most likely factors include the differences in cloud fields, as well as the treatment of cloud effective radii in relation to sulfate loading among models (see further discussion in Sect. 4).

\subsection{Climate responses to sulfate forcing}

The dynamic response of the atmosphere to aerosol forcing will change the cloud fields which, in turn, feedbacks to the radiation fields. As the location of clouds is not directly controlled by aerosols, the indirect forcing may occur at locations different from those of the direct forcing. In Fig. 6b, significant cooling can be found over (but not confined to) the three main areas of pollution sources: Eastern Asia, Central Europe, and Eastern North America. One can also find significant warming between the main cooling areas, such as mid-west Asia, Northern Atlantic and Northern Pacific, as well as some distant regions such as eastern Australia. The temperature change pattern does not have a one-to-one correspondence with the pattern of radiative forcing that is shown in Fig. 6a, indicating that the radiation field has interactions with the dynamic and cloud fields.

The global mean responses of several key climate parameters are summarized in Table 5. The direct forcing (A1-
N1) seems to lead to an increase of global near-surface air temperature by about $0.02 \mathrm{~K}$, but this change also include the $0.03 \mathrm{~K}$ warming from ozone changes as estimated from the $\mathrm{A} 0-\mathrm{N} 0$ results. If we assume the effects interact linearly and back out the ozone effect, the net direct effect would be about $-0.01 \mathrm{~K}$. On the other hand, A2-N2 results give a total cooling of $0.08 \mathrm{~K}$. If we again assume linear interaction and remove both the ozone effect and direct effect, we will get an indirect effect of $-0.10 \mathrm{~K}$. But in reality it is difficult to differentiate contribution of this temperature change from individual effects (e.g. ozone heating, aerosol direct and indirect effects) because their interactions are nonlinear. In addition, due to model internal variability which will be discussed later, the small forcing from ozone heating and aerosol direct effect might not be meaningful. Note that the change in mean surface air temperature here may be underestimated because of the fixed ocean surface temperature.

The indirect effect of anthropogenic sulfate leads to only a slight increase of global cloud coverage by $0.12 \%$ and a depression of precipitation by $0.08 \%$ due to dynamic feedbacks. Note that the results of N0, N1, A0, and A1 may dependent on the choice of effective radius. Yet, the global cloud cover and precipitation does not vary significantly among simulations, indicating that the dynamics of the atmosphere tends to adjust itself in maintaining global stability of clouds and precipitation (in the GCCM).

The global mean forcings seem to be small, but regionally it is a different story. Regional sulfate forcing from GCCM reaches $-5.8 \mathrm{~W} \mathrm{~m}^{-2},-5.9 \mathrm{~W} \mathrm{~m}^{-2}$ and $-4.8 \mathrm{~W} \mathrm{~m}^{-2}$ over the polluted areas in Central Europe $\left(10^{\circ} \mathrm{W} \sim 40^{\circ} \mathrm{E}, 35 \sim 60^{\circ} \mathrm{N}\right)$, Eastern North America $\left(70-100^{\circ} \mathrm{W}, 25-50^{\circ} \mathrm{N}\right)$ and East Asia $\left(105 \sim 135^{\circ} \mathrm{W}, 25 \sim 45^{\circ} \mathrm{N}\right)$, causing surface cooling of $-0.64 \mathrm{~K},-0.14 \mathrm{~K}$ and $-0.53 \mathrm{~K}$, respectively. Such strong forcings may even lead to changes in the monsoon system. 
In East Asia for example, weaker summer monsoon and stronger winter monsoon emerge under the forcing of anthropogenic sulfate, leading to reduced moisture flux from the ocean to the East Asian continent in both seasons. The changes are in many aspects similar to those simulated with the regional coupled climate-chemistry model by Huang et al. (2007) who found regional radiative forcing and surface cooling in East Asia (note: area definition might be different from ours) to be $-4.08 \mathrm{~W} \mathrm{~m}^{-2}$ and $-0.35 \mathrm{~K}$, respectively. They also found a reduction of cloud fraction by $0.8 \%$ and precipitation by more than $10 \%$; whereas the values from GCCM $(2.4 \%$, and $10.3 \%$, respectively) are of similar orders. In addition, the two simulation results share similar geographic distribution of reduced precipitation, with the largest change occurring over South-East Asia during summer and winter. The main calculated features of monsoon flow and precipitation changes over East Asia are reasonably consistent with the sulfate forcing effects reported by Liu et al. (2009) who performed global simulations using CAM 3.0 with assimilated aerosols. The dynamic mechanisms of monsoons may differ significantly from region to region, and the responses would be difficult to separate thus cannot be deciphered from the given simulations alone. So we only take the East Asia region to exemplify the convoluted responses and feedbacks due to sulfate forcing.

\subsection{Effect of coupling on sulfate chemistry}

The climate responses discussed above will also alter the transformation, transport, and removal of aerosols, thus forming feedback loops. Because atmospheric sulfate is formed mainly in liquid clouds (about $76 \%$ in A2), while its removal is mainly by precipitation scavenging (about $88 \%$ in A2), any change in the cloud fields could affect sulfate loading. In addition, the changes in circulation and other parameters such as humidity and actinic flux due to sulfate forcing may influence the transport, dry deposition as well as chemical formation of sulfate. These feedbacks exist only when the sulfur chemistry is coupled to processes in the climate model.

To examine the sensitivity of the sulfur cycle to sulfate forcing, it is not proper to compare simulation set of A2$\mathrm{N} 2$ (or A1-N1, A0-N0) as done earlier, because it would only reflect the large differences in emissions. A somewhat better comparison can be performed between either the Aseries or $\mathrm{N}$-series of simulations, as their emissions are the same but the degrees of coupling of sulfate forcing are different. Note that N0, N1, A0 and A1 simulations do include cloud forcing but the calculations are based on specified effective radii. From Table 3 we can see that $\mathrm{SO}_{2}$ and sulfate loadings vary only slightly by about $1 \%$ for different degree of coupling for both the natural and polluted conditions. Such small changes may be related to the stability in global cloud fields as mentioned in the previous section. On the other hand, the responses in sulfate loading are actually quite strong regionally, but may appear to be small when taking global averages. For example, the variation in regional sulfate loading may reach $15 \%$ and $8 \%$ among the N-series and A-series simulations, respectively. Later, we will further discuss whether these changes are significant comparing to model internal variability. In any case, these changes may be too small to cause significant feedbacks to global radiative forcing, but regionally the feedbacks may be significant.

\section{Discussions}

Earlier we showed that sulfate aerosols may exert forcing on several climate parameters including surface temperature, winds, clouds and precipitation. The anthropogenic indirect forcing due to cloud albedo effect seems to be quite significant from the fully coupled A2-N2 results. On the other hand, as indicated from the A1-N1 results, the direct forcing of anthropogenic sulfate is so weak that its signal might not be distinguishable from other effects that have similar or greater magnitudes. For example, the change of gas-phase chemistry (i.e. increasing ozone) due to anthropogenic pollutants could induce similar magnitude of temperature change as indicated by the A0-N0 results where aerosol forcing is not considered. It is important to establish whether the climate responses we saw in the previous section are truly from the aerosol effects or simply noises.

To eliminate the possibility that differences between simulations shown in Tables 4 and 5 simply are due to internal climate variability of the model, we need to understand how large such an internal variability is. In Fig. 7 the response of several parameters is plotted against their internal variability. The response is defined as the difference between two sets of simulations, whereas the internal variability is defined as the monthly or annual anomaly during the 10 years of simulation time using the second set of simulation as the reference. For example, with the mean temperature difference of A2-N2 as the response, the deviation of annual mean temperature of the subtrahend, N2, from their 10-year average will represent the internal variability. Note that in the above example one may also choose the $\mathrm{A} 2$ results to represent the internal variability. As the internal variability in shortwave radiation and surface temperature from simulations of the A-series are a bit smaller than from $\mathrm{N}$-series, the discussion below is based on a stricter standard. Also note the month-to-month plots are similar, thus we show only the annual values.

Figure $7 \mathrm{a}$ shows that the responses of TOA radiation to sulfate indirect forcing (A2-N2) lies consistently between -1.3 and $-2.0 \mathrm{~W} \mathrm{~m}^{-2}$, and they are significantly larger than the internal variability which lies within $\pm 0.3 \mathrm{~W} \mathrm{~m}^{-2}$. But for the ozone forcing (A0-N0) or the sulfate direct forcing (A1-N1) the responses are of similar magnitude as the internal variability. Furthermore, the spread across the one-to-one line indicates they are not consistently larger or smaller than the internal variations. These features are consistent with 
(a)

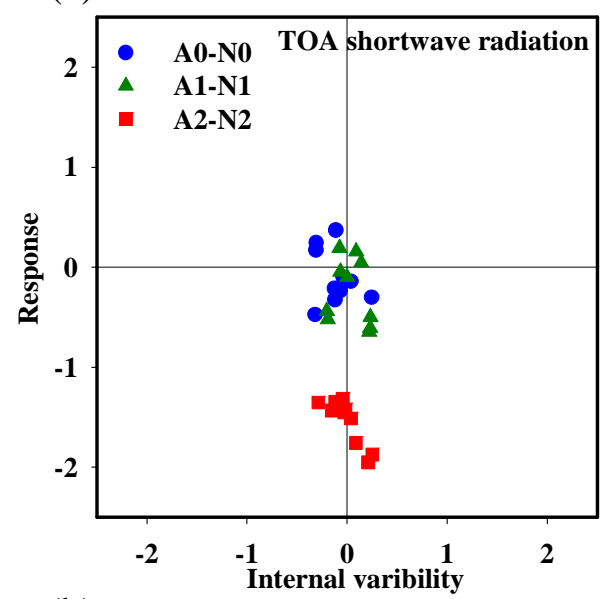

(b)

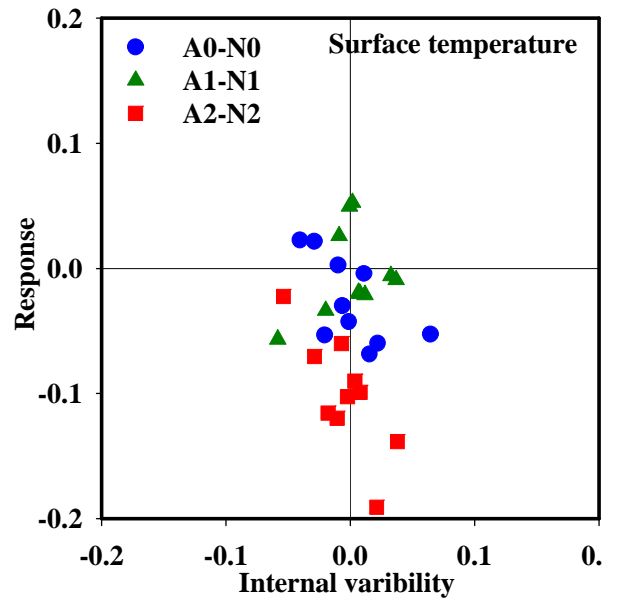

(c)

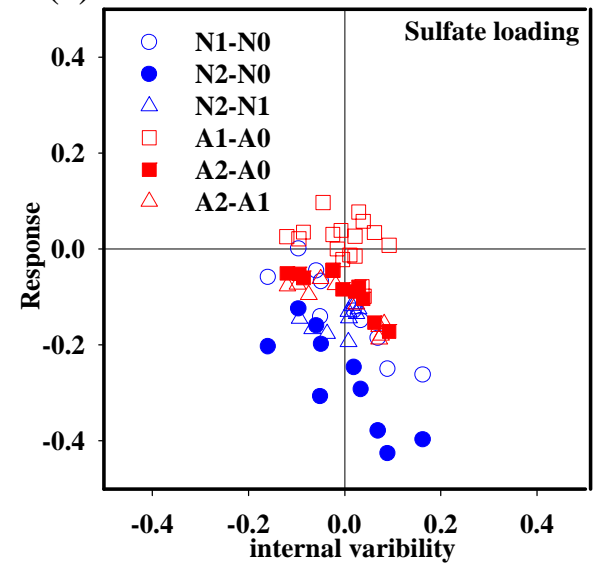

Fig. 7. Comparison between model internal variability (abscissa) and responses to sulfate forcing (ordinate). (a) Global mean TOA radiative forcing (in $\mathrm{W} \mathrm{m}^{-2}$ ); (b) Near-surface temperature (in $\mathrm{K}$ ); and (c) Sulfate loading (in $\mathrm{mg} \mathrm{m}^{-2}$ ). The internal variability is defined as the annual variation of the reference case, which is chosen as the subtrahend of the two simulations being compared (e.g., N0 in $\mathrm{N} 2-\mathrm{N} 0$ ). their statistical significance that listed in Table 4, with only the A2-N2 forcing reaching the $95 \%$ confidence level.

The responses of near-surface temperature (Fig. 7b) to ozone forcing and, in particular, to sulfate direct forcing are again not significant; whereas the responses to indirect forcing of A2-N2 are distinctly larger than the internal variability except one data point, for which year the near-surface temperature still decreases but the amplitude is too small to be regarded as above the noise level. This outlier lowered the certainty of temperature responses, but the statistical significance still reached 95\% (Table 5). The responses in cloud fraction and precipitation change are all indistinguishable from the internal variability, thus their statistical significance are low.

Sulfate itself also responds to the forcing it created, such as changes in circulation and transport patterns, as well as in-cloud chemical production and rain scavenging. As mentioned before, for such feedbacks we need to compare the results of $\mathrm{A} 2-\mathrm{A} 0$ (or $\mathrm{A} 2-\mathrm{A} 1$ ) instead of $\mathrm{A} 2-\mathrm{N} 2$ or $\mathrm{A} 1-\mathrm{N} 1$. Figure $7 \mathrm{c}$ shows that $\mathrm{A} 2-\mathrm{A} 0, \mathrm{~A} 2-\mathrm{A} 1, \mathrm{~N} 2-\mathrm{N} 0$ and $\mathrm{N} 2-\mathrm{N} 1$ give responses in sulfate loading consistently on the negative side. However, only N2-N0 and N2-N1 have responses generally larger than the model variability, thus can be regarded as having clear-cut signals. Note that the annual variations of sulfate loading (in $\mathrm{mg} \mathrm{S} \mathrm{m}^{-2}$ ) in A2 are only half the values in $\mathrm{A} 0$ and $\mathrm{A} 1$. So, if we take the minuend (e.g., A2 in $\mathrm{A} 2-\mathrm{A} 0$ ) as the reference instead, the responses from A2$\mathrm{A} 1$ and A2-A0 would also be regarded as distinctly evident. The magnitude of annual variations seems to decrease with the degree of complexity in the simulation (e.g., with anthropogenic emissions, or with coupled direct or indirect effects). In other words, more controlling mechanisms may lead to a more stable sulfate loading. But the same does not apply to the internal variability of near-surface temperature, cloud fraction and precipitation, which remain similar among the simulations.

Another model uncertainty originates from the treatment of cloud drop effective radii. Recall that the A0 A1, N0 and N1 simulations applied prescribed cloud effective radii, with $10 \mu \mathrm{m}$ over the ocean and $5 \mu \mathrm{m}$ over the continent. Such a treatment gives a radiative forcing very different from that calculated through the empirical formula (2) that used for A2 and $\mathrm{N} 2$ simulations. As can be seen from Table 4, the difference in all-sky radiation between $\mathrm{N} 2$ and $\mathrm{N} 0$ (A2 and A0) may reach $8(10) \mathrm{W} \mathrm{m}^{-2}$, which is much stronger than the indirect forcing of $-1.85 \mathrm{~W} \mathrm{~m}^{-2}$ that discussed earlier. Such differences do contain contributions from the direct aerosol forcing, but the effect should be small as can be seen from the clear-sky values. This implies that the model result is very sensitive to the treatment of cloud drop effective radii and warrants the use of a more sophisticated scheme than using fixed values of 5 or $10 \mu \mathrm{m}$. Figure 8 shows the differences between results using the empirical formula and those with fixed effective radii. One can see that Eq. (2) gives stronger cloud forcing over the oceans but weaker forcing 
(a)

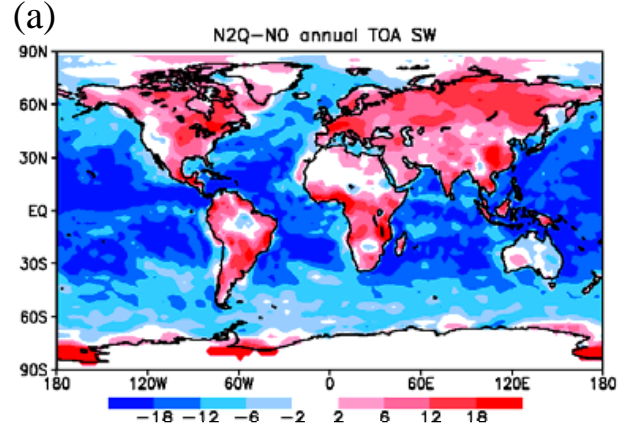

(c)

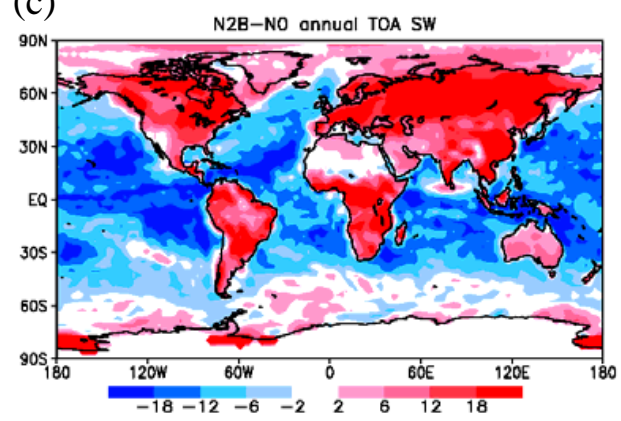

(b)

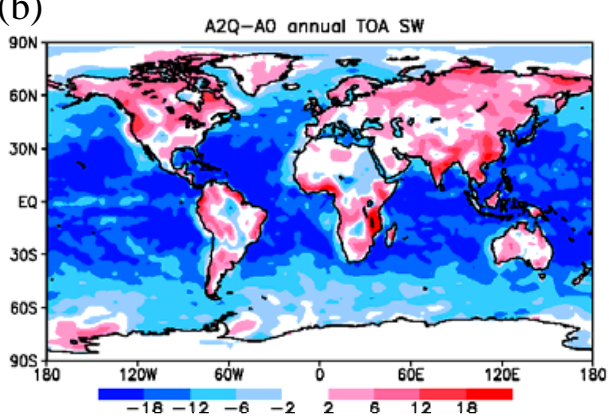

(d)

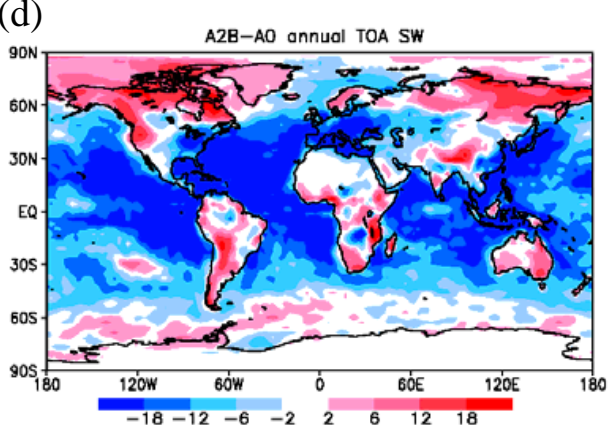

Fig. 8. Differences in all-sky shortwave radiation (in $\mathrm{W} \mathrm{m}^{-2}$ ) between simulations using the empirical formula (2-2) and those with specified effective radii. (a) N2-N0, (b) A2-A0, (c) N2B-N0, and (d) A2B-A0. A2 and N2 applied the coefficients from Quass and Boucher (2005), whereas A2B and B2B applied those from Boucher and Lohmann (1995).

over most of the continents except the highly polluted area such as Northeastern US and Europe in Fig. 8b. Therefore, the size range of effective radii across the continent and ocean is smaller than the specified range of 5 to $10 \mu \mathrm{m}$ in $\mathrm{N} 0$ and $\mathrm{A} 0$, and this seems to be too narrow. We found that the inferred effective radii are still not much less than $5 \mu \mathrm{m}$ even over polluted regions. Furthermore, the differences between A2 and A0 (Fig. 8b) are rather homogeneous over the continents, thus the geographic distribution of anthropogenic sulfate that shown in Fig. $3 \mathrm{~b}$ is not reflected in the sulfate forcing. But over the oceans, the difference is prominent downwind of the pollution sources, indicating a more sensitive relationship between sulfur loading and effective radius.

The original coefficients for Eq. (2) from Boucher and Lohmann (1995) give much stronger dependences of clouddrop number concentration on sulfate loading. When we apply them for the calculations in A2 and N2 (hereafter named $\mathrm{A} 2 \mathrm{~B}$ and $\mathrm{N} 2 \mathrm{~B}$ ), the differences in cloud forcing indeed become obvious also over the polluted continents (Fig. 8d), while those for natural conditions in Fig. 8c remain similar in spatial distribution but lower in magnitude than those using the adjusted coefficients in Fig. 8a as they should be. However, the global sulfate forcing (A2B-N2B) now exceeds $-7 \mathrm{~W} \mathrm{~m}^{-2}$, which is much too high as compared with the estimations given in ICCP (2007). So, it is troublesome that the observation-based and seemly more reasonable relationship between drop number and sulfate loading from Boucher and
Lohmann (1995) overestimate the sulfate indirect forcing, whereas the relationship of Quass and Boucher (2005) that constrained total forcing (to give reasonable results) does not produce reasonable variations in effective radii. One possible explanation is that the incoming shortwave radiation sees mainly the cloud top, not deep inside the cloud or near the cloud base where the measurements of sulfate loading and cloud drop number were performed. Due to various numberreduction processes (such as coalescence, accretion, evaporation due to Bergeron-Findeisen conversion, entrainment mixing or sedimentation), the number of cloud drops tends to vary significantly with height. The microphysical properties near the top of clouds (particularly those high enough to be glaciated partly or fully) might not respond significantly to the change in sulfate loading. It is also possible that Eq. (2) is an oversimplification, as the cloud-drop number concentration actually depends on the size spectrum and chemical composition of the aerosol particles in addition to the strength of updraft. As both the constrained and unconstrained sulfate-effective-radius relationships may contain large uncertainties, more detailed treatment of aerosolcloud interactions are needed in global climate models. Of course, deficiencies in other aspects of cloud representation in global-scale models cannot be ignored either. 


\section{Conclusions}

In this study, we incorporated a sulfur cycle scheme that interact on-line with an extensive gas phase scheme previously included, to take into account emissions, gaseous and aqueous phase chemical processes, and deposition processes, into a Global Climate-Chemistry Model to study the sulfur cycle and the effect of sulfate aerosols on climate through scattering of solar radiation and change of cloud albedo. The seasurface temperature is prescribed in simulations for simplifying the sulfate impacts. If sea-surface temperature is varied, the interactions are much more complicated and difficult to discuss. The coupling of aerosol and cloud radiation with the meteorology not only allowed us to analyze response of the climate parameters but also their feedbacks.

Under a pre-industrial sulfur emission scenario, over $74 \%$ of the atmospheric $\mathrm{SO}_{2}$ is produced by DMS oxidation, the rest by volcanic activities. Whereas $74 \%$ of $\mathrm{SO}_{2}$ is converted to sulfate in the atmosphere and in clouds, and nearly all of the rest is removed by dry deposition. Sulfate is produced mainly by in-cloud oxidation ( $4 \%$ with ozone and $60 \%$ with $\mathrm{H}_{2} \mathrm{O}_{2}$ ), and $89 \%$ of it is removed by wet deposition. Adding the 1985 anthropogenic sulfur emission, which accounts for $78 \%$ of the total $\mathrm{SO}_{2}$ production, global burden of $\mathrm{SO}_{2}$ and sulfate both nearly tripled. About $63 \%$ of $\mathrm{SO}_{2}$ convert to sulfate, and the weighting of sulfate production by in-cloud ozone oxidation increases to $10 \%$, while the fractions by $\mathrm{H}_{2} \mathrm{O}_{2}$ oxidation and gas-phase $\mathrm{OH}$ reaction decrease to $52 \%$ and $11 \%$, respectively. Wet deposition is still the dominating sink for sulfate, accounting for $88 \%$ of the loss; whereas dry deposition dominates the removal of $\mathrm{SO}_{2}$, accounting for $95 \%$ of the loss. Atmospheric lifetimes of $\mathrm{SO}_{2}$, sulfate and total sulfur calculated from GCCM are 1.7, and 2.0 and 2.9 days, respectively, under polluted conditions. Due to its relatively short lifetime, anthropogenic $\mathrm{SO}_{2}$ stays mostly over the populated continents and the nearby oceans, as well as over the shipping corridors. Being a secondary compound and a slightly longer lifetime allows sulfate to disperse further downstream of the prevailing winds than $\mathrm{SO}_{2}$. Anthropogenic sulfate can be transported to rather high altitudes. Over northern hemispheric mid-latitudes, more than $50 \%$ of the $\mathrm{SO}_{2}$ and sulfate near the tropopause (at a height of $300 \mathrm{hPa}$ ) may be of anthropogenic origin.

With the 1985 emissions, global mean sulfate burden increased from the natural condition of $0.10 \mathrm{Tg} \mathrm{S}$ to $0.33 \mathrm{Tg} \mathrm{S}$. The increase of sulfate may cause a reduction of global incoming solar radiation by about $0.24 \mathrm{~W} \mathrm{~m}^{-2}$ from the direct scattering (under all-sky conditions), and by $1.85 \mathrm{~W} \mathrm{~m}^{-2}$ from the enhancement of cloud albedo. Such radiative forcings may cause global mean temperature to decrease by about $0.1 \mathrm{~K}$. Other climate parameters also seem to respond vaguely to sulfate forcing, such as the slight increase in global cloud fraction and reduction of global precipitation. Radiative forcing and temperature response can be much higher on a regional scale, reaching $-5.8 \mathrm{~W} \mathrm{~m}^{-2}$ and
$-0.64 \mathrm{~K}$ in Central Europe, $-5.9 \mathrm{~W} \mathrm{~m}^{-2}$ and $-0.14 \mathrm{~K}$ in Eastern North America and $-4.8 \mathrm{~W} \mathrm{~m}^{-2}$ and $-0.53 \mathrm{~K}$ in East Asia, but the responses in clouds and precipitation can be quite different from the global mean, such as increasing cloudiness in Central Europe and North America but increasing clear sky in East Asia.

By designing a series of simulations that turn on and off the anthropogenic sulfur emissions or the sulfate aerosol effects, we demonstrated that climate signals from the direct forcing of sulfate are indistinguishable from the internal climate variability of the model. The indirect forcing, on the other hand, gives clear signals of climate responses. Note that these results are shown in the context of the variability of the 10-year simulation, not the full model variability. The indirect forcing of sulfate not only changed the meteorological fields but also slightly affected sulfate itself.

Note that we take the sulfur cycle and sulfate radiative forcing as the foci in studying the effects of chemistryclimate interaction on a global scale. It is quite clear that the regional climate variability becomes an outstanding issue to address properly the interaction. In this regard, further study of using coupled atmosphere-ocean model is warranted. The ocean component may produce additional feedbacks (either positive or negative) which might be significant as the ocean occupies $70 \%$ of the global surface. This certainly adds to the uncertainty in model's internal variability. In addition, uncertainties in the treatment of aerosol-cloud interactions remain rather large, thus improvements are deemed necessary for better understanding of the aerosol effect on global climate. A plausible approach is to apply the fully coupled regional models, which are able to use more complicated and physically based algorithms, and can serve to develop more effective parameterizations for the chemistry-climate feedback processes in global models.

Acknowledgements. The study is conducted jointly through the East Asia Climate and Environment (EACE) task, in which the research effort was supported: (at NTU) by NSC 96-2752-M002-013-PAE, NSC 97-2752-M-002-012-PAE, NSC 97-2111-M002-002, and NSC 98-2111-M-002-001; and (at SUNYA) by the Office of Science (BER), US Department of Energy. It is also partially supported by the Academia Sinica through the thematic project "Atmospheric Forcing on Ocean Biogeochemistry (AFOBi).

Edited by: A. Hofzumahaus

\section{References}

Albrecht, B. A.: Aerosols, cloud microphysics, and fractional cloudiness, Science, 245, 1227-1230, 1989.

Amels, P., Elias, H., Götz, U., Steingens, U., and Wannowius, K. $\mathrm{J}$.: Kinetic investigation of the stability of peroxonitric acid and of its reaction with sulfur (IV) in aqueous solution. in: Heterogeneous and Liquid Phase Processes, Springer-Verlag, New York, USA, 77-88, 1996. 
Anderson, T. L., Charlson, R. J., Schwartz, S. E., Knutti, R., Boucher, O., Rodhe, H., and Heintzenberg, J.: Climate forcing by aerosols - a hazy picture, Science, 300, 1103-1104, 2003.

Audiffren, N., Buisson, E., Cautenet, S., and Chaumerliac, N.: Photolytic impact of a stratocumulus cloud layer upon the chemistry of an offshore advected plume of pollutants during the NARE 1993 intensive experiment: a numerical study, Atmos. Res., 70, 89-108, 2004.

Benkovitz, C. M., Scholtz, M. T., Pacyna, J., Tarraso'n, L., Dignon, J., Voldner, E. C., Spiro, P. A., Logan, J. A., and Graedel, T. E.: Global gridded inventories of anthropogenic emissions of sulfur and nitrogen, J. Geophys. Res., 101, 29239-29253, 1996.

Berglen, T. F., Berntsen, T. K., Isaksen, I. S. A., and Sundet, J. K.: A global model of the coupled sulfur/oxidant chemistry in the troposphere: The sulfur cycle, J. Geophys. Res., 109, D19310, doi:10.1029/2003JD003948, 2004.

Berntsen, T. K. and Isaksen, I. S. A.: A global 3-D chemical transport model for the troposphere; 1 . Model description and CO and ozone results, J. Geophys. Res., 102, 21239-21280, 1997.

Boucher, O. and Anderson, T. L.: General circulation model assessment of the sensitivity of direct climate forcing by anthropogenic sulfate aerosols to aerosol size and chemistry, J. Geophys. Res., 100(D12), 26117-26134, 1995.

Boucher, O. and Lohmann, U.: The sulfate-CCN-cloud albedo effect: A sensitivity study with two general circulation models, Tellus, 47B, 281-300, 1995.

Cerveny, R. S. and Balling Jr., R. C.: Weekly cycles of air pollutants, precipitation and tropical cyclones in the coastal NW Atlantic region, Nature, 394, 561-563, 1998.

Chen, Y. and Penner, J. E.: Uncertainty analysis for estimates of the first indirect aerosol effect, Atmos. Chem. Phys., 5, 2935-2948, 2005, http://www.atmos-chem-phys.net/5/2935/2005/.

Chin, M., Jacob, D. J., Gardner, G. M., Foreman-Fowler, M. S., Spiro, P. A., and Savoie, D. L.: A global three-dimensional model of tropospheric sulfate, J. Geophys. Res., 101, 1866718690, 1996.

Chin, M., Savoie, D. L., Huebert, B. J., Bandy, A. R., Thornton, D. C., Bates, T. S., Quinn, P. K., Saltzman, E. S., and De Bruyn, W. J.: Atmospheric sulfur cycle simulated in the global model GOCART: Comparison with field observations and regional budgets, J. Geophys. Res., 105, 24689-24712, 2000.

Chou, C., Neelin, J. D., Lohmann, U., and Feichter, J.: Local and remote impacts of aerosol climate forcing on tropical precipitation, J. Climate, 18, 4621-4636, 2005.

Chuang, C. C., Penner, J. E., Taylor, K. E., Grossman, A. S., and Walton, J. J.: An assessment of the radiative effects of anthropogenic sulfate, J. Geophys. Res., 102(D3), 3761-3778, 1997.

DeMore, W. B., Sander, S. P., Golden, D. M., Hampson, R. F., Kurylo, M. J., Howard, C. J., Ravishankara, A. R., Kolb, C. E., and Molina, M. J.: Chemical kinetics and photochemical data for use in stratospheric modeling, Tech. Rep. 97-4, Jet Propulsion Lab., Pasadena, California, USA, 1997.

Endresen, Ø., Sørgård, E., Sundet, J. K., Dalsøren, S. B., Isaksen, I. S. A., Berglen, T. F., and Gravir, G.: Emission from international sea transportation and environment impact, J. Geophys. Res., 108(D17), 4560, doi:10.1029/2002JD002898, 2003.

Eyring, V., Köhler, H. W., van Aardenne, J., and Lauer, A.: Emission from international shipping: 1. The last 50 years, J. Geophys. Res., 110, D17305, doi:10.1029/2004JD005619, 2005.
Feichter, J., Kjellström, E., Rodhe, H., Dentener, F., Lelieveld, J., and Roelofs, G. J.: Simulation of the tropospheric sulfur cycle in a global climate model, Atmos. Environ., 30(10-11), 16931707, 1996.

Forkel, R. and Knoche, R.: Regional climate change and its impact on photooxidant concentrations in southern Germany: Simulations with a coupled regional climate-chemistry model, J. Geophys. Res., 111, D12302, doi:10.1029/2005JD006748, 2006.

Gates, W. L., Boyle, J., Covey, C., Dease, C., Doutriaux, C., Drach, R., Fiorino, M., Gleckler, P., Hnilo, J., Marlais, S., Phillips, T., Potter, G., Santer, B., Sperber, K., Taylor, K. and Williams, D.: An overview of the results of the Atmospheric Model Intercomparison Project (AMIP I), B. Am. Meteorol. Soc., 80, 29-55, 1999.

Ghan, S., Easter, R., Chapman, E., Abdul-Razzak, H., Zhang, Y., Leung, R., Laulainen, N., Saylor, R. D., and Zaveri, R.: A physically-based estimate of radiative forcing by anthropogenic sulphate aerosol, J. Geophys. Res., 106(D6), 52795294, doi:10.1029/2000JD900503, 2001.

Giorgi, F., Bi, X., and Qian, Y.: Direct radiative forcing and regional climatic effects of anthropogenic aerosols over East Asia: a regional coupled climate-chemistry/aerosol model study, J. Geophys. Res., 107(D16), 4439, doi:10.1029/2001JD001274, 2002.

Graft, H., Feichter, J., and Langmann, B.: Volcanic sulfur emissions: Estimates of sources strength and its contribution to the global sulfate distribution, J. Geophys. Res., 102, 10727-10738, 1997.

Grell, G. A., Peckham, S. E., Schmitz, R., McKeen, S. A., Frost, G., Skamarock, W. C., and Eder, B.: Fully coupled "online" chemistry within the WRF model, Atmos. Environ., 39, 6957-6975, 2005.

Gu, Y., Liou, K. N., Xue, Y., Mechoso, C. R., Li, W. and Luo, Y.: Climatic effects of different aerosol types in China simulated by the UCLA general circulation model, J. Geophys. Res., 111, D15201, doi:10.1029/2005JD006312, 2006.

Hack, J. J., Kiehl, J. T., and Hurrell, J. W.: The hydrologic and thermodynamic characteristics of the NCAR CCM3, J. Clim., 11, 1179-1206, 1998.

Hansen, J., Sato, M. and Ruedy, R.: Radiative forcing and climate response, J. Geophys. Res., 102(D6), 6831-6864, 1997.

Haywood, J. M. and Shine, K. P.: Multi-spectral calculations of the direct radiative forcing of tropospheric sulphate and soot aerosols using a column model, Q. J. Roy. Meteorol. Soc., 123, 19071930, 1997.

Haywood, J. M., Ramaswamy, V., and Soden, B. J.: Tropospheric aerosol climate forcing in clear-sky satellite observations over the oceans, Science, 283, 1299-1305, 1999.

Huang, Y., Chameides, W. L., and Dickinson, R. E.: Direct and indirect effects of anthropogenic aerosols on regional precipitation over East Asia, J. Geophys. Res., 112, D03212, doi:10.1029/2006JD007114, 2007.

IPCC: Climate Change 2007: The Physical Science Basis. Contribution of Working Group I to the Fourth Assessment Report of the Intergovernmental Panel on Climate Change, edited by: Solomon, S., Qin, D., Manning, M., Chen, Z., Marquis, M., Averyt, K. B., Tignor, M., and Miller, H. L., Cambridge Univ. Press, Cambridge, UK, and New York, USA, 153-171, 2007.

Isaksen, I. S. A., and Hov, Ø.: Calculations of trends in the tropospheric concentrations of $\mathrm{O}_{3}, \mathrm{OH}, \mathrm{CO}, \mathrm{CH}_{4}$, and $\mathrm{NO}_{\mathrm{x}}$, Tellus, 
Ser. B, 39, 271-283, 1987.

Iversen, T., Kirkevåg, A., Kristjansson, J. E., and Seland, Ø.: Climate effects of sulphate and black carbon estimated in a global climate model, in: Air Pollution Modeling and its Application XIV, Kluwer/Plenum Publishers, New York, USA, 335-342, 2000.

Iversen, T. and Seland, Ø.: A scheme for process-tagged SO4 and BC aerosols in NCAR CCM3: Validation and sensitivity to cloud processes, J. Geophys. Res., 107(D24), 4751, doi:10.1029/2001JD000885, 2002.

Jacobson, M. Z.: Global direct radiative forcing due to multicomponent anthropogenic and natural aerosols, J. Geophys. Res., 106, 1551-1568, 2001.

Jacobson, M. Z., Lu, R., Turco, R. P., and Toon, O. B., Development and application of a new air pollution modelsystem - Part I: Gasphase simulations, Atmos. Environ., 30 1939-1963, 1996.

Jockel, P., Sander, R., Kerkweg, A., Tost, H. and Lelieveld, J.: Technical Note: The Modular Earth Submodel System (MESSy) - a new approach towards Earth System Modeling, Atmos. Chem. Phys., 5, 433-444, 2005,

http://www.atmos-chem-phys.net/5/433/2005/.

Jones, A., Roberts, D. L., and Woodage, M. J.: Indirect sulphate aerosol forcing in a climate model with an interactive sulphur cycle, J. Geophys. Res. 106, 20293-20310, 2001.

Jones, A., Haywood, J. M., and Boucher, O.: Aerosol forcing, climate response and climate sensitivity in the Hadley Centre climate model, J. Geophys. Res., 112, D20211, doi:10.1029/2007JD008688, 2007.

Kaufman, Y. J. and Fraser, R. S.: The effect of smoke particles on clouds and climate forcing, Science, 277(5332), 1636-1638, 1997.

Kettle, A. J., Andreae, M. O., Amouroux, D., et al.: A global database of sea surface dimethylsulfide (DMS) measurements and a procedure to predict sea surface DMS as a function of latitude, longitude and month, Global Biogeochem. Cy., 13(2), 399-444, 1999.

Kettle, A. J., and Andreae, M. O.: Flux of dimethylsulfide from the oceans: A comparison of updated data seas and flux models, J. Geophys. Res., 105(D22), 26793-26808, 2000.

Kiehl, J. T. and Briegleb, B. P.: The relative roles of sulfate aerosols and greenhouse gases in climate forcing, Science, 260, 311-314, 1993.

Kiehl, J. T. and Rodhe, H.: Modeling geographical and seasonal forcing due to aerosols, in: Aerosol Forcing of Climate, J. Wiley and Sons Ltd, 281-296, 1995.

Kiehl, J.T., Schneider, T. L., Rasch, P. J., Barth, M. C., and Wong, J.: Radiative forcing due to sulfate aerosols from simulations with the National Center for Atmospheric Research Community Climate Model, Version 3, J. Geophys. Res., 105(D1), 1441-1457, 2000.

Koch, D., Jacob, D. J., Tegen, I., Rind, D. and Chin, M.: Tropospheric sulfur simulation and sulfate direct radiative forcing in the Goddard Institute for Space Studies general circulation model, J. Geophys. Res., 104, 23799-23822, 1999.

Koch, D.: Transport and direct radiative forcing of carbonaceous and sulfate aerosols in the GISS GCM, J. Geophys. Res., 106(D17), 20311-20332, 2001.

Kukui, A., Borissenko, D., Laverdet, G., and Le Bras, G.: Gasphase reactions of $\mathrm{OH}$ radicals with dimethyl sulfoxide and methane sulfinic acid using turbulent flow reactor and chemical ionization mass spectrometry, J. Phys. Chem., 107, 5732-5742, 2003.

Langner, J. and Rodhe, H.: A global three-dimensional model of the tropospheric sulfur cycle, J. Atmos. Chem., 13, 225-263, 1991.

Lau, K.-M., Kim, J. H., and Sud, Y.: Intercomparison of hydrological processes in AMIP GCMs, B. Amer. Meteorol. Soc., 77, 2209-2227, 1996.

Liss, E. S. and Galloway, J. N.: Air-sea exchange of sulfur and nitrogen and their interaction in the marine atmosphere, edited by: Wollast, R., MacKenzie, E. T., and Chou, I., in: Interactions of C, N, P and S Biogeochemical Cycles and Global Change, NATO ASI Series, Vol. 14, Springer-Veflag, Berlin, Heidelberg, Germany, 113-127, 1993.

Liss, P. S. and Merlivat, L.: Air-sea gas exchange rates: Introduction and synthesis, in: The Role of Air-Sea Exchange in Geochemical Cycling, D. Reidel, Norwell, Mass., USA, 113-127, 1986.

Liu, Y., Sun, J., and Yang, B.: The Effects of Black Carbon and Sulfate Aerosols in China Regions on East Asia Monsoons, Tellus B, 61, 642-656, 2009

Lohmann, U. and Feichter, J.: Global indirect aerosol effects: A review, Atmos. Chem. Phys., 5, 715-737, 2005, http://www.atmos-chem-phys.net/5/715/2005/.

Martin, G. M., Johnson, D. W., and Spice, A.: The measurements and parameterization of effective radius of droplets in warm stratocumulus clouds, J. Atmos. Sci., 51, 1823-1842, 1994.

Martin, L. R. and Damschen, D. E.: Aqueous oxidation of sulfur dioxide by hydrogen peroxide at low pH, Atmos. Environ., 15, 1615-1621, 1981.

Mickley, L. J., Murti, P. P., Jacob, D. J., Logan, J. A., Koch, D. M., and Rind, D.: Radiative forcing from tropospheric ozone calculated with a unified chemistry-climate model, J. Geophys. Res., 104, 30153-30172, 1999.

Mitchell, J. F. B., Johns T. C., Gregory, J. M., and Tett, F. B.: Climate response to increasing levels of greenhouse gases and sulphate aerosols, Nature, 376, 501-504, 1995.

Moller, D.: Kinetic model of atmospheric $\mathrm{SO}_{2}$ oxidation based on published data, Atmos. Environ., 14, 1067-1076, 1980.

Myhre, G., Stordal, F., Restad, K., and Isaksen, I. S. A.: Estimation of the direct radiative forcing due to sulphate and soot aerosols, Tellus, 50B, 463-477, 1998.

Penner, J. E., Chuang, C. C., and Grant, K.: Climate forcing by carbonaceous and sulphate aerosols, Clim. Dynam., 14, 839-851, 1998.

Quaas, J. and Boucher, O.: Constraining the first aerosol indirect radiative forcing in the LMDZ GCM using POLDER and MODIS satellite data, Geophys. Res. Lett., 32, L17814, doi:10.1029/2005GL023850, 2005.

Ramanathan, V., Crutzen, P. J., Kiehl, J. T., and Rosenfeld, D.: Aerosols, climate, and the hydrological cycle, Science, 294, 2119-2124, 2001.

Restad, K., Isaksen, I. S. A., and Berntsen, T. K.: Global distribution of sulfate in the troposphere: A three-dimensional model study, Atmos. Environ., 32, 3593-3609, 1998.

Rodhe, H. and Isaksen, I. S. A.: Global distribution of sulfur compounds in the troposphere estimated in a height/latitude transport model, J. Geophys. Res., 85, 7401-7409, 1980.

Roelofs, G.-J., Lelieveld, J., and Ganzeveld, L.: Simulation of global sulfate distribution and the influence on effective cloud 
drop radii with a coupled photochemistry-sulfur cycle model, Tellus, Ser.B, 50, 224-242, 1998.

Rosenfeld, D.: Suppression of Rain and Snow by Urban and Industrial Air Pollution, Science, 287(5459), 1793-1796, 2000.

Rotstayn, L. D. and Penner, J. E.: Indirect aerosol forcing, quasiforcing, and climate response, J. Climate, 14, 2960-2975, 2001.

Saltzman, E. S., Savoie, D. L., Prospero, J. M., and Zika, R. G.: Methanesulfonic acid and non-sea-salt sulfate in Pacific air: Regional and seasonal variation, J. Atmos. Chem., 4, 227-240.

Schulz, M., Textor, C., Kinne, S., Balkanski, Y., Bauer, S., Berntsen, T., Berglen, T., Boucher, O., Dentener, F., Guibert, S., Isaksen, I. S. A., Iversen, T., Koch, D., Kirkevag, A., Liu, X., Montanaro, V., Myhre, G., Penner, J. E., Pitari, G., Reddy, S., Seland, O., Stier, P., and Takemura, T.: Radiative forcing by aerosols as derived from the AeroCom present-day and preindustrial simulations, Atmos. Chem. Phys., 6, 5225-5246, 2006

Senior, C. A. and Mitchell, J. F. B.: Carbon dioxide and climate: The impact of cloud parameterization, J. Clim., 6, 393-418, 1993.

Shindell, D. T., Grenfell, J. L., Rind, D., Grewe, V., and Price, C.: Chemistry-climate interaction in the GISS general circulation model:1. Tropospheric chemistry model description and evaluation, J. Geophys. Res., 106, 8047-8076, 2001.

Simo, R.: From cells to globe: approaching the dynamics of DMS(P) in the ocean at multiple scales, Can. J. Fish. Aquat. Sci., 61, 673-684, 2004.

Sorensen, S., Falbe-Hansen, H., and Hjorth, J.: Observation of DMSO and $\mathrm{CH}_{3} \mathrm{~S}(\mathrm{O}) \mathrm{OH}$ from the gas phase reaction between DMS and OH, J. Atmos. Chem. 24, 299-315, 1996.

Spiro, P. A., Jacob, D. J., and Logan, J. A.: Global Inventory of Sulfur Emission with $1^{\circ} \times 1^{\circ}$ resolution, J. Geophys. Res., 97, 6023-6036, 1992.

Textor, C., Schulz, M., Guibert, S., Kinne, S., Balkanski, Y., Bauer, S., Berntsen, T., Berglen, T., Boucher, O., Chin, M., Dentener, F., Diehl, T., Easter, R., Feichter, H., Fillmore, D., Ghan, S., Ginoux, P., Gong, S., Grini, A., Hendricks, J., Horowitz, L., Huang, P., Isaksen, I., Iversen, I., Kloster, S., Koch, D., Kirkevåg, A., Kristjansson, J. E., Krol, M., Lauer, A., Lamarque, J. F., Liu, X., Montanaro, V., Myhre, G., Penner, J., Pitari, G., Reddy, S., Seland, Ø., Stier, P., Takemura, T., and Tie, X.: Analysis and quantification of the diversities of aerosol life cycles within AeroCom, Atmos. Chem. Phys., 6, 1777-1813, 2006,

http://www.atmos-chem-phys.net/6/1777/2006/.
Twomey, S.: Pollution and the planetary albedo, Atmos. Environ., 8, 1251-1256, 1974.

Van Dorland, R., Dentener, F. J., and Lelieveld, J.: Radiative forcing due to tropospheric ozone and sulfate aerosols, J. Geophys. Res., 102 (D23), 28079-28100, 1997.

Williams, K. D., Jones, A., Roberts, D. L., Senior, C. A., and Woodage, M. J.: The response of the climate system to the indirect effects of anthropogenic sulfate aerosols, Clim. Dyn., 17, 845-856, 2001.

Wang, W.-C., Liang, X. Z., Dudek, M. P., Pollard, D., and Thompson, S. L.: Atmospheric ozone as a climate gas, Atmos. Res., 37, 247-256, 1995.

Wong, S. and Wang, W.-C.: Interhemispheric asymmetry in the seasonal variation of the zonal mean tropopause, J. Geophys. Res. 105, 26645-26659, 2000.

Wong, S. and Wang, W.-C.: Tropical-extratropical connection in interannual variation of the tropopause: Comparison between NCEP/NCAR reanalysis and an atmospheric general circulation model, J. Geophys. Res., 108 (D2), 4043 , doi:10.1029/2001JD002016, 2003.

Wong, S., Wang, W.-C., Isaksen, I. S. A., Berntsen, T. K., and Sundet, J. K.: A global climate-chemistry model study of presentday tropospheric chemistry and radiative forcing from changes in tropospheric $\mathrm{O}_{3}$ since the preindustrial period, J. Geophys. Res., 109, D11309, doi:10.1029/2003JD003998, 2004.

Zhang, Y. C.: Online-coupled meteorology and chemistry models: history, current status, and outlook, Atmos. Chem. Phys., 8, 2895-2932, 2008, http://www.atmos-chem-phys.net/8/2895/2008/. 